\title{
Well-posedness for systems of generalized mixed quasivariational inclusion problems and optimization problems with constraints
}

\author{
Lu-Chuan Cenga ${ }^{a}$, Yeong-Cheng Liou ${ }^{b, c, *}$, Jen-Chih Yao ${ }^{d}$, Yonghong Yao ${ }^{e}$, Ching-Hua Lo ${ }^{f, *}$ \\ a Department of Mathematics, Shanghai Normal University, Shanghai 200234, China. \\ ${ }^{b}$ Department of Healthcare Administration and Medical Informatics, Center for Big Data Analytics \& Intelligent Healthcare, and \\ Research Center of Nonlinear Analysis and Optimization, Kaohsiung Medical University, Kaohsiung 807, Taiwan. \\ ${ }^{c}$ Department of Medical Research, Kaohsiung Medical University Hospital, Kaohsiung 807, Taiwan. \\ ${ }^{d}$ Center for General Education, China Medical University, Taichung, 40402, Taiwan. \\ ${ }^{e}$ Department of Mathematics, Tianjin Polytechnic University, Tianjin 300387, China. \\ ${ }^{f}$ Center for Big Data Analytics \& Intelligent Healthcare, and Department of Healthcare Administration and Medical Informatics, \\ Kaohsiung Medical University, Kaohsiung 807, Taiwan.
}

Communicated by G. Marino

\begin{abstract}
In this paper, several metric characterizations of well-posedness for systems of generalized mixed quasivariational inclusion problems and for optimization problems with systems of generalized mixed quasivariational inclusion problems as constraints are given. The equivalence between the well-posedness of systems of generalized mixed quasivariational inclusion problems and the existence of solutions of systems of generalized mixed quasivariational inclusion problems is given under suitable conditions. (C)2017 All rights reserved.
\end{abstract}

Keywords: Well-posedness, metric characterization, system of generalized mixed quasivariational inclusion problems, optimization problem with constraint.

2010 MSC: 49J40, 49J27, 90C31.

\section{Introduction}

It is well-known that the concept of well-posedness has played an important role in the study of optimization theory. The classical concept of well-posedness for a minimization problem is due to Tykhonov [25], which is known as the Tykhonov well-posedness. A minimization problem is called Tykhonov well-posed if there hold two aspects: the existence and uniqueness of minimizers and the convergence of every minimizing sequence toward the unique minimizer. It is clear that the concept of Tykhonov well-posedness is inspired by the numerical methods producing optimizing sequences for optimization

\footnotetext{
*Corresponding authors

Email addresses: zenglc@hotmail.com (Lu-Chuan Ceng), simplex_liou@hotmail.com (Yeong-Cheng Liou), yaojc@kmu .edu.tw (Jen-Chih Yao), yaoyonghong@aliyun.com (Yonghong Yao), bde_lo@sina.com (Ching-Hua Lo)

doi:10.22436/jnsa.010.10.23
} 
problems. The concept of generalized Tykhonov well-posedness is also introduced for a minimization problem having more than one solution, which means the existence of minimizers and the convergence of some subsequence of every minimizing sequence toward a minimizer. Another important concept of wellposedness for a minimization problem is well-posedness by perturbations or extended well-posedness due to Zolezzi [32, 33]. The concept of well-posedness by perturbations establishes a form of continuous dependence of the solutions upon a parameter. There are many other concepts of well-posedness in optimization problems. For more details, we refer the reader to $[6,19,23]$ and the references therein.

The concept of well-posedness has been generalized to some other problems: variational inequality problems $[5,6,9,10,13,16,19,29]$, saddle point problems[4], Nash equilibrium problems [20, 21], inclusion problems $[9,15]$, and fixed point problems $[9,15,22]$.

Let $\mathrm{P}$ be a nonempty closed subset of a normed space, $\mathrm{C}$ be a nonempty closed convex subset of a real Banach space, $\mathrm{g}: \mathrm{P} \times \mathrm{C} \times \mathrm{C} \rightarrow \mathbf{R}$ and $\mathrm{h}: \mathrm{P} \times \mathrm{C} \rightarrow \mathbf{R}$ be functions. Recently, Fang et al. [9] considered the following problems: for $p \in P$,

$$
(E P)_{p}: \quad \text { Find } x \in C \text { such that } g(p, x, u) \geqslant 0 \text {, for all } u \in C \text {, }
$$

and

$$
\text { (OPEP): } \operatorname{minh}(p, x) \text { subject to } x \text { is a solution of }(E P)_{p} \text {. }
$$

They established some metric characterizations of well-posedness for equilibrium problems and for optimization problems with equilibrium constraints. Furthermore, they proved that under suitable conditions, the well-posedness is equivalent to the existence and uniqueness of solutions, and that the well-posedness in the generalized sense is equivalent to the existence of solutions.

In recent years, the study of well-posedness for equilibrium problems has received so much attention and many results of well-posedness have been obtained for variational equilibrium problems (see e.g., $[2,8,18]$ and the references therein). In 2009, Lin and Chuang [17] studied the well-posedness in the generalized sense for variational inclusion problems and variational disclusion problems, the well-posedness for optimization problems with variational inclusion problems, variational disclusion problems and scalar equilibrium problems as constraints.

The quasivariational inclusion problem is an important generalization of the variational inclusion problem, which contains a lot of important problems as special cases and has many applications, like variational disclusion problems, minimax inequalities, equilibrium problems, saddle point problems, optimization problems, bilevel problems, mathematical program with equilibrium constraint, variational inequalities, fixed point problems, coincidence point problems, Ekeland's variational principle, etc. For more details, we refer the reader to $[4,11,12,24,27,28,30,31]$ and the references therein. In 2009, Long and Huang [18] generalized the concept of $\alpha$-well-posedness to symmetric quasiequilibrium problems in Banach spaces, which include equilibrium problems, Nash equilibrium problems, quasivariational inequalities, variational inequalities, and fixed-point problems as special cases. Under some suitable conditions, they established some metric characterizations of $\alpha$-well-posedness for symmetric quasiequilibrium problems. In 2012, Ceng and Lin [3] generalized the concept of $\alpha$-well-posedness to systems of mixed quasivariational-like inequalities in Banach spaces, which include symmetric quasiequilibrium problems as special cases. Moreover, they derived some metric characterizations of $\alpha$-well-posedness for the system of mixed quasivariational-like inequalities. Very recently, Wang et al. [26] introduced and studied well-posedness of generalized quasivariational inclusion problems and of optimization problems with generalized quasivariational inclusion problems as constraints.

Motivated and inspired by the works mentioned above, in this paper, we shall investigate wellposedness for systems of generalized mixed quasivariational inclusion problems and for optimization problems with systems of generalized mixed quasivariational inclusion problems as constraints. We establish some metric characterizations of well-posedness for systems of generalized mixed quasivariational inclusion problems and for optimization problems with systems of generalized mixed quasivariational inclusion problems as constraints. We also prove that under mild conditions, the well-posedness of systems 
of generalized mixed quasivariational inclusion problems is equivalent to the existence and uniqueness of solutions, and that the well-posedness in the generalized sense of systems of generalized mixed quasivariational inclusion problems is equivalent to the existence of solutions.

\section{Preliminaries}

In this section, we recall some definitions and lemmas used in the sequel.

Definition 2.1 ([1]). Let $X$ and $Y$ be two topological spaces. A multivalued mapping $T: X \rightarrow 2^{Y}$ is said to be

(i) upper semicontinuous (for short, u.s.c.) at $x \in X$, if for each open set $V$ in $Y$ with $T(x) \subseteq V$, there exists an open neighborhood $\mathrm{U}(\mathrm{x})$ of $\mathrm{x}$ such that $\mathrm{T}(\mathrm{u}) \subseteq \mathrm{V}$ for all $\mathrm{u} \in \mathrm{U}(\mathrm{x})$;

(ii) lower semicontinuous (for short, 1.s.c.) at $x \in X$, if for each open set $V$ in $Y$ with $T(x) \cap V \neq \emptyset$, there exists an open neighborhood $\mathrm{U}(\mathrm{x})$ of $x$ such that $\mathrm{T}(\mathrm{u}) \cap \mathrm{V} \neq \emptyset$ for all $u \in U(x)$;

(iii) u.s.c. (resp., 1.s.c.) on $X$ if it is u.s.c. (resp., l.s.c.) at every point $x \in X$;

(iv) continuous on $X$ if it is both u.s.c. and l.s.c. on $X$;

(v) closed if the graph of $T$ is closed, i.e., the set $\operatorname{Gr}(T)=\{(x, y) \in X \times Y: y \in T(x)\}$ is closed in $X \times Y$.

Lemma 2.2 ([1]). Let $\mathrm{X}$ and $\mathrm{Y}$ be two topological spaces and $\mathrm{F}: \mathrm{X} \rightarrow 2^{\mathrm{Y}}$ be a multivalued mapping.

(i) If $\mathrm{F}$ is u.s.c. and closed-valued, then $\mathrm{F}$ is closed.

(ii) If $\mathrm{F}$ is compact-valued, then $\mathrm{F}$ is u.s.c. at $\mathrm{x} \in \mathrm{X}$ if and only if for any net $\left\{x_{\alpha}\right\} \subseteq \mathrm{X}$ with $\mathrm{x}_{\alpha} \rightarrow \mathrm{x}$ and for any net $\left\{y_{\alpha}\right\} \subseteq Y$ with $y_{\alpha} \in F\left(x_{\alpha}\right)$ for all $\alpha$, there exist $y \in F(x)$ and a subnet $\left\{y_{\beta}\right\}$ of $\left\{y_{\alpha}\right\}$ such that $y_{\beta} \rightarrow y$.

(iii) $\mathrm{F}$ is l.s.c. at $\mathrm{x} \in \mathrm{X}$ if and only if for any $\mathrm{y} \in \mathrm{F}(\mathrm{x})$ and for any net $\left\{x_{\alpha}\right\}$ with $\mathrm{x}_{\alpha} \rightarrow \mathrm{x}$, there exists a net $\left\{\mathrm{y}_{\alpha}\right\}$ with $\mathrm{y}_{\alpha} \in \mathrm{F}\left(\mathrm{x}_{\alpha}\right)$ for all $\alpha$ such that $\mathrm{y}_{\alpha} \rightarrow \mathrm{y}$.

Definition 2.3 ([14]). Let $S$ be a nonempty subset of a complete metric space $(X, d)$. The Kuratowski measure of noncompactness of $S$ is defined by

$$
\mu(S)=\inf \left\{\varepsilon>0: S \subseteq \bigcup_{i=1}^{n} S_{i}, \operatorname{diam} S_{i}<\varepsilon, i=1,2, \cdots, n\right\},
$$

where diam $S_{i}$ denotes the diameter of set $S_{i}$ and is defined by diam $S_{i}=\sup \left\{d\left(x_{1}, x_{2}\right): x_{1}, x_{2} \in S_{i}\right\}$.

Definition 2.4. Let $(X, d)$ be a metric space and let $U, V$ be nonempty subsets of $X$. The Hausdorff metric $\mathcal{H}(\cdot, \cdot)$ between $\mathrm{U}$ and $\mathrm{V}$ is defined by

$$
\mathcal{H}(\mathrm{U}, \mathrm{V}):=\max \{e(\mathrm{U}, \mathrm{V}), e(\mathrm{~V}, \mathrm{U})\}
$$

where $e(U, V):=\sup _{u \in U} d(u, V)$ with $d(u, V)=\inf _{v \in V} d(u, v)$. Let $\left\{U_{n}\right\}$ be a sequence of nonempty subsets of $X$. One says that $U_{n}$ converges to $U$ in the sense of Hausdorff metric if $\mathcal{H}\left(U_{n}, U\right) \rightarrow 0$. It is easy to see that $e\left(U_{n}, U\right) \rightarrow 0$ if and only if $d\left(u_{n}, U\right) \rightarrow 0$ for all sections $u_{n} \in U_{n}$. For more details on this topic, we refer the readers to [14].

Definition 2.5. Let $(E, \rho)$ be a metric space which is also a vector space. $(E, \rho)$ is said to be a linear metric space if $E$ is a vector topological space in the topology induced by $\rho$.

\section{Well-posedness for systems of generalized mixed quasivariational inclusion problems}

Let $\left(\mathcal{P}, \mathrm{d}_{0}\right)$ be a metric space and $P$ be a nonempty closed subset of $\mathcal{P}$. Let $(X, \hat{\mathrm{d}})$ and $(\mathrm{Y}, \overline{\mathrm{d}})$ be two linear metric spaces, $\mathrm{Z}$ be a Hausdorff topological vector space, $\mathrm{C} \subseteq \mathrm{X}$ and $\mathrm{D} \subseteq \mathrm{Y}$ be two nonempty closed subsets. Let $f, g: P \times C \times D \rightarrow Z$ be two single-valued mappings. Let $S: C \times D \rightarrow 2^{C}, T: C \times D \rightarrow 2^{D}$, $\mathrm{G}: \mathrm{P} \times \mathrm{X} \times \mathrm{Y} \times \mathrm{X} \rightarrow 2^{\mathrm{Z}}$ and $\mathrm{F}: \mathrm{P} \times \mathrm{Y} \times \mathrm{X} \times \mathrm{Y} \rightarrow 2^{\mathrm{Z}}$ be multivalued mappings. Let $\hat{e}: \mathrm{C} \rightarrow \mathrm{Z}$ and $\bar{e}: \mathrm{D} \rightarrow \mathrm{Z}$ be two continuous mappings. Throughout this paper, unless otherwise specified, we use these notations and assumptions. 
We consider the following parametric system of generalized mixed quasivariational inclusion problems. For $p \in P,(S G M Q V I P)_{p}$ : find a point $(x, y) \in S(x, y) \times T(x, y)$ such that

$$
\begin{cases}0 \in G(p, x, y, u)+f(p, x, y)-f(p, u, y), & \forall u \in S(x, y), \\ 0 \in F(p, y, x, v)+g(p, x, y)-g(p, x, v), & \forall v \in T(x, y) .\end{cases}
$$

Denote by (SGMQVIP) the family $\left\{(\text { SGMQVIP })_{p}: p \in P\right\}$. For each $p \in P$, let $S_{p}$ be the solution set of $(\mathrm{SGMQVIP})_{\mathrm{p}}$.

In particular, if we set $f=0$ and $g=0$, the parametric system of generalized mixed quasivariational inclusion problems reduces to the following parametric system of generalized quasivariational inclusion problems. For $p \in P,(S G Q V I P)_{p}$ : find a point $(x, y) \in S(x, y) \times T(x, y)$ such that

$$
\begin{cases}0 \in \mathrm{G}(\mathrm{p}, \mathrm{x}, \mathrm{y}, \mathrm{u}), & \forall \mathrm{u} \in \mathrm{S}(\mathrm{x}, \mathrm{y}) \\ 0 \in \mathrm{F}(\mathrm{p}, \mathrm{y}, \mathrm{x}, v), & \forall v \in \mathrm{T}(\mathrm{x}, \mathrm{y})\end{cases}
$$

Denote by (SGQVIP) the family $\left\{(\mathrm{SGQVIP})_{\mathrm{p}}: \mathrm{p} \in \mathrm{P}\right\}$. For each $\mathrm{p} \in \mathrm{P}$, let $\mathrm{S}_{\mathrm{p}}$ be the solution set of $(\mathrm{SGQVIP})_{\mathrm{p}}$.

Let $\mathcal{D}$ be a metric space. For each $a \in \mathcal{D}$ and each $r>0$, we denote by $B(a, r)$ the closed ball centered at a with radius $r$. When $\mathcal{D}=\mathbf{R}$, we denote by $B^{+}(0, r)$ the closed interval $[0, r]$.

Definition 3.1. Let $p \in P$ and let $\left\{p_{n}\right\} \subseteq P$ be any sequence such that $p_{n} \rightarrow p$. A sequence $\left\{\left(x_{n}^{*}, y_{n}^{*}\right)\right\} \subset$ $\mathrm{C} \times \mathrm{D}$ is called an approximating solution sequence for (SGMQVIP $)_{p}$ corresponding to $\left\{\mathrm{p}_{n}\right\}$ if for each $n \in \mathbf{N},\left(x_{n}^{*}, y_{n}^{*}\right) \in S\left(x_{n}^{*}, y_{n}^{*}\right) \times T\left(x_{n}^{*}, y_{n}^{*}\right)$, and there exist $\left(x_{n}, y_{n}\right) \in S\left(x_{n}^{*}, y_{n}^{*}\right) \times T\left(x_{n}^{*}, y_{n}^{*}\right)$ and a sequence $\varepsilon_{n}>0$ with $\varepsilon_{n} \rightarrow 0$ such that

$$
\begin{cases}\hat{d}\left(x_{n}, x_{n}^{*}\right) \leqslant \hat{d}\left(x_{n}, S\left(x_{n}, y_{n}\right)\right), \quad \bar{d}\left(y_{n}, y_{n}^{*}\right) \leqslant \bar{d}\left(y_{n}, T\left(x_{n}, y_{n}\right)\right), & \\ 0 \in G\left(p_{n}, x_{n}^{*}, y_{n}, u\right)+f\left(p_{n}, x_{n}^{*}, y_{n}\right)-f\left(p_{n}, u, y_{n}\right)+B^{+}\left(0, \varepsilon_{n}\right) \hat{e}\left(x_{n}^{*}\right), & \forall u \in S\left(x_{n}^{*}, y_{n}^{*}\right), \\ 0 \in F\left(p_{n}, y_{n}^{*}, x_{n}, v\right)+g\left(p_{n}, x_{n}, y_{n}^{*}\right)-g\left(p_{n}, x_{n}, v\right)+B^{+}\left(0, \varepsilon_{n}\right) \bar{e}\left(y_{n}^{*}\right), & \forall v \in T\left(x_{n}^{*}, y_{n}^{*}\right) .\end{cases}
$$

Definition 3.2. (SGMQVIP) is said to be well-posed if for every $p \in P,(S G M Q V I P)_{p}$ has a unique solution $\left(x_{p}, y_{p}\right)$, and for every sequence $\left\{p_{n}\right\} \subseteq P$ with $p_{n} \rightarrow p$, every approximating solution sequence for $(S G M Q V I P)_{p}$ corresponding to $\left\{p_{n}\right\}$ converges to $\left(x_{p}, y_{p}\right)$, and (SGMQVIP) is said to be well-posed in the generalized sense if for every $p \in P,(S G M Q V I P)_{p}$ has a nonempty solution set $S_{p}$, and for every sequence $\left\{p_{n}\right\} \subseteq P$ with $p_{n} \rightarrow p$, every approximating solution sequence for (SGMQVIP) $p$ corresponding to $\left\{p_{n}\right\}$ has a subsequence which converges to some point of $S_{p}$.

Remark 3.3.

(a) When $(\mathrm{SGMQVIP})_{\mathfrak{p}}$ reduces to $(\mathrm{SGQVIP})_{\mathfrak{p}}$, we have a definition of approximating solution sequence for $(\mathrm{SGQVIP})_{p}$ and definitions of well-posedness and well-posedness in the generalized sense for (SGQVIP).

(b) The definition of approximating solution sequence for $(\mathrm{SGQVIP})_{\mathrm{p}}$ generalizes that of Wang et al. [26].

(c) The definition of approximating solution sequence for $(\mathrm{GQVIP})_{p}$ in [26] generalizes that of Lin and Chuang [17].

For each $p \in P$, the approximating solution set for $(\mathrm{SGMQVIP})_{\mathrm{p}}$ is defined by

$$
\begin{aligned}
\Omega_{\mathfrak{p}}(\delta, \varepsilon)=\bigcup_{p^{\prime} \in B(p, \delta)}\{ & \left(x^{*}, y^{*}\right) \in C \times D:\left(x^{*}, y^{*}\right) \in S\left(x^{*}, y^{*}\right) \times T\left(x^{*}, y^{*}\right), \text { and } \\
& \exists(x, y) \in S\left(x^{*}, y^{*}\right) \times T\left(x^{*}, y^{*}\right) \text { s.t. } \hat{d}\left(x, x^{*}\right) \leqslant \hat{d}(x, S(x, y)), \bar{d}\left(y, y^{*}\right) \leqslant \bar{d}(y, T(x, y)), \\
& 0 \in G\left(p^{\prime}, x^{*}, y, u\right)+f\left(p^{\prime}, x^{*}, y\right)-f\left(p^{\prime}, u, y\right)+B^{+}(0, \varepsilon) \hat{e}\left(x^{*}\right), \forall u \in S\left(x^{*}, y^{*}\right), \\
& \left.0 \in F\left(p^{\prime}, y^{*}, x, v\right)+g\left(p^{\prime}, x, y^{*}\right)-g\left(p^{\prime}, x, v\right)+B^{+}(0, \varepsilon) \bar{e}\left(y^{*}\right), \quad \forall v \in T\left(x^{*}, y^{*}\right)\right\},
\end{aligned}
$$


for all $\delta, \varepsilon>0$. Clearly, we have, for every $p \in P$,

(i) $S_{p} \subseteq \Omega_{p}(\delta, \varepsilon)$ for all $\delta, \varepsilon>0$;

(ii) if $0<\delta_{1} \leqslant \delta_{2}$ and $0<\varepsilon_{1} \leqslant \varepsilon_{2}$, then $\Omega_{p}\left(\delta_{1}, \varepsilon_{1}\right) \subseteq \Omega_{\mathfrak{p}}\left(\delta_{2}, \varepsilon_{2}\right)$.

Next, we further establish some properties of $\Omega_{p}(\delta, \varepsilon)$.

Proposition 3.4. Assume that

(i) S and T are compact-valued;

(ii) for each $(x, y) \in C \times D$, single-valued mappings $(p, v) \mapsto f(p, x, v)$ and $(p, u) \mapsto g(p, u, y)$ are continuous;

(iii) for each $(x, u, y, v) \in C \times C \times D \times D$, multivalued mappings $(p, t) \mapsto G(p, x, t, u)$ and $(p, s) \mapsto F(p, y, s, v)$ are closed;

(iv) for each $\left(x^{*}, y^{*}\right) \in \bigcap_{\delta>0, \varepsilon>0} \Omega_{p}(\delta, \varepsilon)$, the convergence of $\left(x_{n}, y_{n}\right)\left(\in S\left(x^{*}, y^{*}\right) \times T\left(x^{*}, y^{*}\right), n \in N\right)$ implies $\hat{\mathrm{d}}\left(x_{n}, S\left(x_{n}, y_{n}\right)\right) \rightarrow 0$ and $\overline{\mathrm{d}}\left(y_{n}, T\left(x_{n}, y_{n}\right)\right) \rightarrow 0$.

Then $S_{p}=\bigcap_{\delta>0, \varepsilon>0} \Omega_{p}(\delta, \varepsilon)$ for each $p \in P$.

Proof. Take a fixed $\mathrm{p} \in \mathrm{P}$ arbitrarily. Clearly, $\mathrm{S}_{\mathrm{p}} \subseteq \bigcap_{\delta>0, \varepsilon>0} \Omega_{\mathrm{p}}(\delta, \varepsilon)$. Hence, we only need to show that $\bigcap_{\delta>0, \varepsilon>0} \Omega_{\mathfrak{p}}(\delta, \varepsilon) \subseteq S_{p}$. If not, then there exists $\left(x^{*}, y^{*}\right) \in \bigcap_{\delta>0, \varepsilon>0} \Omega_{\mathfrak{p}}(\delta, \varepsilon)$ such that $\left(x^{*}, y^{*}\right) \notin S_{p}$. Then, for each $\delta>0$ and each $\varepsilon>0,\left(x^{*}, y^{*}\right) \in \Omega_{\mathfrak{p}}(\delta, \varepsilon) \backslash S_{p}$. Thus, for each $n \in \mathbf{N},\left(x^{*}, y^{*}\right) \in \Omega_{\mathfrak{p}}\left(\frac{1}{n}, \frac{1}{n}\right) \backslash S_{p}$, and so there exist $p_{n} \in B\left(p, \frac{1}{n}\right)$ and $\left(x_{n}, y_{n}\right) \in S\left(x^{*}, y^{*}\right) \times T\left(x^{*}, y^{*}\right)$ such that

$$
\begin{gathered}
\hat{d}\left(x_{n}, x^{*}\right) \leqslant \hat{d}\left(x_{n}, S\left(x_{n}, y_{n}\right)\right), \bar{d}\left(y_{n}, y^{*}\right) \leqslant \bar{d}\left(y_{n}, T\left(x_{n}, y_{n}\right)\right), \\
\begin{cases}0 \in G\left(p_{n}, x^{*}, y_{n}, u\right)+f\left(p_{n}, x^{*}, y_{n}\right)-f\left(p_{n}, u, y_{n}\right)+B^{+}\left(0, \frac{1}{n}\right) \hat{e}\left(x^{*}\right), & \forall u \in S\left(x^{*}, y^{*}\right), \\
0 \in F\left(p_{n}, y^{*}, x_{n}, v\right)+g\left(p_{n}, x_{n}, y^{*}\right)-g\left(p_{n}, x_{n}, v\right)+B^{+}\left(0, \frac{1}{n}\right) \bar{e}\left(y^{*}\right), & \forall v \in T\left(x^{*}, y^{*}\right) .\end{cases}
\end{gathered}
$$

Clearly, $p_{n} \rightarrow p$. Since $\left\{y_{n}\right\} \subseteq T\left(x^{*}, y^{*}\right)$ and $T\left(x^{*}, y^{*}\right)$ is a compact set, there exists a subsequence $\left\{y_{n_{k}}\right\}$ of $\left\{y_{n}\right\}$ such that $y_{n_{k}} \rightarrow \bar{y}$ as $k \rightarrow \infty$, and so, for each $k \in \mathbf{N}$,

$$
0 \in G\left(p_{n_{k}}, x^{*}, y_{n_{k}}, u\right)+f\left(p_{n_{k}}, x^{*}, y_{n_{k}}\right)-f\left(p_{n_{k}}, u, y_{n_{k}}\right)+B^{+}\left(0, \frac{1}{n_{k}}\right) \hat{e}\left(x^{*}\right), \forall u \in S\left(x^{*}, y^{*}\right) .
$$

For each $u \in S\left(x^{*}, y^{*}\right)$, by (3.1), for every $k \in \mathbf{N}$, there exists $\hat{\gamma}_{k} \in B^{+}\left(0, \frac{1}{n_{k}}\right)$ such that

$$
0 \in G\left(p_{n_{k}}, x^{*}, y_{n_{k}}, u\right)+f\left(p_{n_{k}}, x^{*}, y_{n_{k}}\right)-f\left(p_{n_{k}}, u, y_{n_{k}}\right)+\hat{\gamma}_{k} \hat{e}\left(x^{*}\right) .
$$

Meantime, for each $v \in T\left(x^{*}, y^{*}\right)$ and each $k \in \mathbf{N}$, we know that there exists $\bar{\gamma}_{k} \in B^{+}\left(0, \frac{1}{n_{k}}\right)$ such that

$$
0 \in F\left(p_{n_{k}}, y^{*}, x_{n_{k}}, v\right)+g\left(p_{n_{k}}, x_{n_{k}}, y^{*}\right)-g\left(p_{n_{k}}, x_{n_{k}}, v\right)+\bar{\gamma}_{k} \bar{e}\left(y^{*}\right)
$$

Clearly, $p_{n_{k}} \rightarrow p$ as $k \rightarrow \infty$. Since $\left\{x_{n_{k}}\right\} \subseteq T\left(x^{*}, y^{*}\right)$ and $T\left(x^{*}, y^{*}\right)$ is a compact set, there exists a subsequence of $\left\{x_{n_{k}}\right\}$, denoted still by $\left\{x_{n_{k}}\right\}$, such that $x_{n_{k}} \rightarrow \hat{x}$ as $k \rightarrow \infty$.

Clearly, $\hat{\gamma}_{k} \rightarrow 0$ and $\bar{\gamma}_{k} \rightarrow 0$ as $k \rightarrow \infty$. Since $(p, y) \mapsto G\left(p, x^{*}, y, u\right)$ is closed, $(p, y) \mapsto f\left(p, x^{*}, y\right)$ and $(p, y) \mapsto f(p, u, y)$ are continuous and (3.2) holds, we get

$$
0 \in G\left(p, x^{*}, \bar{y}, u\right)+f\left(p, x^{*}, \bar{y}\right)-f(p, u, \bar{y}) .
$$

Meantime, since $(p, x) \mapsto G\left(p, y^{*}, x, v\right)$ is closed, $(p, x) \mapsto g\left(p, x, y^{*}\right)$ and $(p, x) \mapsto g(p, x, v)$ are continuous and (3.3) holds, we get

$$
0 \in F\left(p, y^{*}, \hat{x}, v\right)+g\left(p, \hat{x}, y^{*}\right)-g(p, \hat{x}, v) .
$$


Furthermore, by the definition of metric $d(\cdot, \cdot)$ in the product space $(X \times Y, d)$, we deduce that

$$
d\left(\left(x_{n_{k}}, y_{n_{k}}\right),(\hat{x}, \bar{y})\right)=\sqrt{\left(\hat{d}\left(x_{n_{k}}, \hat{x}\right)\right)^{2}+\left(\bar{d}\left(y_{n_{k}}, \bar{y}\right)\right)^{2}} \leqslant \hat{d}\left(x_{n_{k}}, \hat{x}\right)+\bar{d}\left(y_{n_{k}}, \bar{y}\right) \rightarrow 0 .
$$

From condition (iv) and the convergence of $\left\{\left(x_{n_{k}}, y_{n_{k}}\right)\right\} \subseteq S\left(x^{*}, y^{*}\right) \times T\left(x^{*}, y^{*}\right)$ to $(\hat{x}, \bar{y})$, it follows that $\hat{\mathrm{d}}\left(x_{n_{k}}, S\left(x_{n_{k}}, y_{n_{k}}\right)\right) \rightarrow 0$ and $\bar{d}\left(y_{n_{k}}, T\left(x_{n_{k}}, y_{n_{k}}\right)\right) \rightarrow 0$ as $k \rightarrow \infty$. Thus,

$$
\hat{d}\left(\hat{x}, x^{*}\right)=\lim _{k \rightarrow \infty} \hat{d}\left(x_{n_{k}}, x^{*}\right) \leqslant \lim _{k \rightarrow \infty} \hat{d}\left(x_{n_{k}}, S\left(x_{n_{k}}, y_{n_{k}}\right)\right)=0
$$

and

$$
\overline{\mathrm{d}}\left(\overline{\mathrm{y}}, \mathrm{y}^{*}\right)=\lim _{\mathrm{k} \rightarrow \infty} \overline{\mathrm{d}}\left(\mathrm{y}_{\mathrm{n}_{\mathrm{k}}}, \mathrm{y}^{*}\right) \leqslant \lim _{\mathrm{k} \rightarrow \infty} \mathrm{d}\left(\mathrm{y}_{\mathrm{n}_{\mathrm{k}}}, \mathrm{T}\left(\mathrm{x}_{\mathrm{n}_{\mathrm{k}}}, \mathrm{y}_{\mathrm{n}_{\mathrm{k}}}\right)\right)=0 .
$$

So, we get $\hat{x}=x^{*}$ and $\bar{y}=y^{*}$. Consequently, from (3.4) and (3.5) we have

$$
\begin{cases}0 \in \mathrm{G}\left(\mathrm{p}, \mathrm{x}^{*}, \mathrm{y}^{*}, \mathrm{u}\right)+\mathrm{f}\left(\mathrm{p}, \mathrm{x}^{*}, \mathrm{y}^{*}\right)-\mathrm{f}\left(\mathrm{p}, \mathrm{u}, \mathrm{y}^{*}\right), & \forall \mathrm{u} \in \mathrm{S}\left(\mathrm{x}^{*}, \mathrm{y}^{*}\right), \\ 0 \in \mathrm{F}\left(\mathrm{p}, \mathrm{y}^{*}, \mathrm{x}^{*}, v\right)+\mathrm{g}\left(\mathrm{p}, \mathrm{x}^{*}, \mathrm{y}^{*}\right)-\mathrm{g}\left(\mathrm{p}, \mathrm{x}^{*}, v\right), & \forall v \in \mathrm{T}\left(\mathrm{x}^{*}, \mathrm{y}^{*}\right) .\end{cases}
$$

That is, $\left(x^{*}, y^{*}\right) \in S_{p}$, which is a contradiction. Hence, $\bigcap_{\delta>0, \varepsilon>0} \Omega_{p}(\delta, \varepsilon) \subseteq S_{p}$ and so

$$
S_{p}=\bigcap_{\delta>0, \varepsilon>0} \Omega_{p}(\delta, \varepsilon)
$$

This completes the proof.

\section{Proposition 3.5. Assume that}

(i) S and T are continuous and compact-valued;

(ii) for each $\mathrm{p} \in \mathrm{P}$, single-valued mappings $(\mathrm{x}, \mathrm{y}) \mapsto \mathrm{f}(\mathrm{p}, \mathrm{x}, \mathrm{y})$ and $(\mathrm{x}, \mathrm{y}) \mapsto \mathrm{g}(\mathrm{p}, \mathrm{x}, \mathrm{y})$ are continuous;

(iii) for each $\mathrm{p} \in \mathrm{P}$, multivalued mappings $(\mathrm{x}, \mathrm{y}, \mathrm{u}) \mapsto \mathrm{G}(\mathrm{p}, \mathrm{x}, \mathrm{y}, \mathrm{u})$ and $(\mathrm{y}, \mathrm{x}, \mathrm{v}) \mapsto \mathrm{F}(\mathrm{p}, \mathrm{y}, \mathrm{x}, \mathrm{v})$ are closed;

(iv) for each convergent sequence $\left\{\left(x_{n}^{*}, y_{n}^{*}\right)\right\} \subseteq S_{p}$, the convergence of $\left(x_{n}, y_{n}\right)\left(\in S\left(x_{n}^{*}, y_{n}^{*}\right) \times T\left(x_{n}^{*}, y_{n}^{*}\right)\right.$, $\mathrm{n} \in \mathbf{N})$ implies $\hat{\mathrm{d}}\left(\mathrm{x}_{\mathrm{n}}, \mathrm{S}\left(\mathrm{x}_{\mathrm{n}}, \mathrm{y}_{\mathrm{n}}\right)\right) \rightarrow 0$ and $\overline{\mathrm{d}}\left(\mathrm{y}_{\mathrm{n}}, \mathrm{T}\left(\mathrm{x}_{\mathrm{n}}, \mathrm{y}_{\mathrm{n}}\right)\right) \rightarrow 0$.

Then $S_{p}$ and

$$
\begin{aligned}
\left\{\left(x^{*}, y^{*}\right) \in C \times D\right. & :\left(x^{*}, y^{*}\right) \in S\left(x^{*}, y^{*}\right) \times T\left(x^{*}, y^{*}\right), \text { and } \exists(x, y) \in S\left(x^{*}, y^{*}\right) \times T\left(x^{*}, y^{*}\right) \text { s.t. } \\
& \hat{d}\left(x, x^{*}\right) \leqslant \hat{d}(x, S(x, y)), \bar{d}\left(y, y^{*}\right) \leqslant \bar{d}(y, T(x, y)), \\
& 0 \in G\left(p, x^{*}, y, u\right)+f\left(p, x^{*}, y\right)-f(p, u, y)+B^{+}(0, \varepsilon) \hat{e}\left(x^{*}\right), \forall u \in S\left(x^{*}, y^{*}\right), \\
& \left.0 \in F\left(p, y^{*}, x, v\right)+g\left(p, x, y^{*}\right)-g(p, x, v)+B^{+}(0, \varepsilon) \bar{e}\left(y^{*}\right), \forall v \in T\left(x^{*}, y^{*}\right)\right\},
\end{aligned}
$$

are closed subsets of $\mathrm{C} \times \mathrm{D}$.

Proof. (i) Take a fixed $p \in P$ arbitrarily. If $\left(x^{*}, y^{*}\right) \in \operatorname{cls}_{p}$, then there exists a sequence $\left\{\left(x_{n}^{*}, y_{n}^{*}\right)\right\}$ in $S_{p}$ such that $\left(x_{n}^{*}, y_{n}^{*}\right) \rightarrow\left(x^{*}, y^{*}\right)$ (i.e., $x_{n}^{*} \rightarrow x^{*}$ and $\left.y_{n}^{*} \rightarrow y^{*}\right)$ as $n \rightarrow \infty$. It follows that, for each $n \in \mathbf{N},\left(x_{n}^{*}, y_{n}^{*}\right) \in S\left(x_{n}^{*}, y_{n}^{*}\right) \times T\left(x_{n}^{*}, y_{n}^{*}\right)$ and there exists some $\left(x_{n}, y_{n}\right) \in S\left(x_{n}^{*}, y_{n}^{*}\right) \times T\left(x_{n}^{*}, y_{n}^{*}\right)$ such that $\hat{\mathrm{d}}\left(x_{n}, x_{n}^{*}\right) \leqslant \hat{\mathrm{d}}\left(x_{n}, S\left(x_{n}, y_{n}\right)\right), \overline{\mathrm{d}}\left(y_{n}, y_{n}^{*}\right) \leqslant \overline{\mathrm{d}}\left(y_{n}, T\left(x_{n}, y_{n}\right)\right)$,

$$
\begin{cases}0 \in G\left(p, x_{n}^{*}, y_{n}, u\right)+f\left(p, x_{n}^{*}, y_{n}\right)-f\left(p, u, y_{n}\right), & \forall u \in S\left(x_{n}^{*}, y_{n}^{*}\right), \\ 0 \in F\left(p, y_{n}^{*}, x_{n}, v\right)+g\left(p, x_{n}, y_{n}^{*}\right)-g\left(p, x_{n}, v\right), & \forall v \in T\left(x_{n}^{*}, y_{n}^{*}\right) .\end{cases}
$$

Since $S$ is u.s.c. and closed-valued, $S$ is closed and so $x^{*} \in S\left(x^{*}, y^{*}\right)$. Since $T$ is u.s.c. and compactvalued, there exist a subsequence $\left\{y_{n_{k}}\right\}$ of $\left\{y_{n}\right\}$ and $\bar{y} \in T\left(x^{*}, y^{*}\right)$ such that $y_{n_{k}} \rightarrow \bar{y}$ as $k \rightarrow \infty$. It follows 
that, for each $k \in \mathbf{N}$,

$$
0 \in G\left(p, x_{n_{k}}^{*}, y_{n_{k}}, u\right)+f\left(p, x_{n_{k}}^{*}, y_{n_{k}}\right)-f\left(p, u, y_{n_{k}}\right), \quad \forall u \in S\left(x_{n_{k}}^{*}, y_{n_{k}}^{*}\right) .
$$

For each $u \in S\left(x^{*}, y^{*}\right)$, since $S$ is l.s.c., there exists a sequence $\left\{u_{n_{k}}\right\}$ with $u_{n_{k}} \in S\left(x_{n_{k}}^{*}, y_{n_{k}}^{*}\right)$ such that $u_{k} \rightarrow u$ as $k \rightarrow \infty$, and so

$$
0 \in G\left(p, x_{n_{k}}^{*}, y_{n_{k}}, u_{k}\right)+f\left(p, x_{n_{k}}^{*}, y_{n_{k}}\right)-f\left(p, u_{k}, y_{n_{k}}\right) .
$$

Next, for each $k \in \mathbf{N}$, we get the following relation associated with (3.6)

$$
0 \in F\left(p, y_{n_{k}}^{*}, x_{n_{k}}, v\right)+g\left(p, x_{n_{k}}, y_{n_{k}}^{*}\right)-g\left(p, x_{n_{k}}, v\right), \quad \forall v \in T\left(x_{n_{k}}^{*}, y_{n_{k}}^{*}\right) .
$$

Since $T$ is u.s.c. and closed-valued, $T$ is closed and so $y^{*} \in T\left(x^{*}, y^{*}\right)$. Since $S$ is u.s.c. and compactvalued, there exist a subsequence of $\left\{x_{n_{k}}\right\}$, denoted still by $\left\{x_{n_{k}}\right\}$, and $\hat{x} \in S\left(x^{*}, y^{*}\right)$ such that $x_{n_{k}} \rightarrow \hat{x}$ as $k \rightarrow \infty$. Moreover, for each $v \in T\left(x^{*}, y^{*}\right)$, since $T$ is l.s.c., there exists a sequence $\left\{v_{k}\right\}$ with $v_{k} \in T\left(x_{n_{k}}^{*}, y_{n_{k}}^{*}\right)$ such that $v_{\mathrm{k}} \rightarrow v$ as $\mathrm{k} \rightarrow \infty$, and so

$$
0 \in F\left(p, y_{n_{k}}^{*}, x_{n_{k}}, v_{k}\right)+g\left(p, x_{n_{k}}, y_{n_{k}}^{*}\right)-g\left(p, x_{n_{k}}, v_{k}\right)
$$

Since multivalued mappings $(x, y, u) \mapsto G(p, x, y, u)$ and $(y, x, v) \mapsto F(p, y, x, v)$ are closed and singlevalued mappings $(u, y) \mapsto f(p, u, y)$ and $(x, v) \mapsto g(p, x, v)$ are continuous, we obtain from (3.7) and (3.8) that

$$
\begin{cases}0 \in G\left(p, x^{*}, \bar{y}, u\right)+f\left(p, x^{*}, \bar{y}\right)-f(p, u, \bar{y}), & \forall u \in S\left(x^{*}, y^{*}\right), \\ 0 \in F\left(p, y^{*}, \hat{x}, v\right)+g\left(p, \hat{x}, y^{*}\right)-g(p, \hat{x}, v), & \forall v \in T\left(x^{*}, y^{*}\right) .\end{cases}
$$

From condition (iv) and the convergence of $\left(x_{n_{k}}, y_{n_{k}}\right)\left(\in S\left(x_{n_{k}}^{*}, y_{n_{k}}^{*}\right) \times T\left(x_{n_{k}}^{*}, y_{n_{k}}^{*}\right), k \in N\right)$ to $(\hat{x}, \bar{y})$, it follows that $\hat{d}\left(x_{n_{k}}, S\left(x_{n_{k}}, y_{n_{k}}\right)\right) \rightarrow 0$ and $\bar{d}\left(y_{n_{k}}, T\left(x_{n_{k}}, y_{n_{k}}\right)\right) \rightarrow 0$ as $k \rightarrow \infty$. Thus,

$$
\hat{d}\left(\hat{x}, x^{*}\right)=\lim _{k \rightarrow \infty} \hat{d}\left(x_{n_{k}}, x_{n_{k}}^{*}\right) \leqslant \lim _{k \rightarrow \infty} \hat{d}\left(x_{n_{k}}, S\left(x_{n_{k}}, y_{n_{k}}\right)\right)=0,
$$

and

$$
\overline{\mathrm{d}}\left(\bar{y}, y^{*}\right)=\lim _{k \rightarrow \infty} \bar{d}\left(y_{n_{k}}, y_{n_{k}}^{*}\right) \leqslant \lim _{k \rightarrow \infty} d\left(y_{n_{k}}, T\left(x_{n_{k}}, y_{n_{k}}\right)\right)=0 .
$$

So, we get $\hat{x}=x^{*}$ and $\bar{y}=y^{*}$. Consequently, from (3.9) we have

$$
\begin{cases}0 \in G\left(p, x^{*}, y^{*}, u\right)+f\left(p, x^{*}, y^{*}\right)-f\left(p, u, y^{*}\right), & \forall u \in S\left(x^{*}, y^{*}\right), \\ 0 \in F\left(p, y^{*}, x^{*}, v\right)+g\left(p, x^{*}, y^{*}\right)-g\left(p, x^{*}, v\right), & \forall v \in T\left(x^{*}, y^{*}\right) .\end{cases}
$$

That is, $\left(x^{*}, y^{*}\right) \in S_{p}$, which hence implies $\mathrm{cl}_{\mathrm{p}} \subseteq \mathrm{S}_{\mathrm{p}}$. Therefore, $\mathrm{S}_{\mathrm{p}}=\mathrm{cl} \mathrm{S}_{\mathrm{p}}$.

(ii) Take any $p \in P$ and any $\varepsilon>0$ and let $(p, \varepsilon)$ be fixed. Let

$$
\begin{aligned}
A=\left\{\left(x^{*}, y^{*}\right) \in C \times D:\right. & \left(x^{*}, y^{*}\right) \in S\left(x^{*}, y^{*}\right) \times T\left(x^{*}, y^{*}\right), \text { and } \exists(x, y) \in S\left(x^{*}, y^{*}\right) \times T\left(x^{*}, y^{*}\right) \text { s.t. } \\
& \hat{d}\left(x, x^{*}\right) \leqslant \hat{d}(x, S(x, y)), \quad \bar{d}\left(y, y^{*}\right) \leqslant \bar{d}(y, T(x, y)), \\
& 0 \in G\left(p, x^{*}, y, u\right)+f\left(p, x^{*}, y\right)-f(p, u, y)+B^{+}(0, \varepsilon) \hat{e}\left(x^{*}\right), \forall u \in S\left(x^{*}, y^{*}\right), \\
& \left.0 \in F\left(p, y^{*}, x, v\right)+g\left(p, x, y^{*}\right)-g(p, x, v)+B^{+}(0, \varepsilon) \bar{e}\left(y^{*}\right), \quad \forall v \in T\left(x^{*}, y^{*}\right)\right\} .
\end{aligned}
$$

If $\left(x^{*}, y^{*}\right) \in \mathrm{cl} A$, then there exists a sequence $\left\{\left(x_{n}^{*}, y_{n}^{*}\right)\right\}$ in $A$ such that $\left(x_{n}^{*}, y_{n}^{*}\right) \rightarrow\left(x^{*}, y^{*}\right)$ as $n \rightarrow \infty$. It follows that, for each $n \in \mathbf{N},\left(x_{n}^{*}, y_{n}^{*}\right) \in S\left(x_{n}^{*}, y_{n}^{*}\right) \times T\left(x_{n}^{*}, y_{n}^{*}\right)$ and there exists some $\left(x_{n}, y_{n}\right) \in S\left(x_{n}^{*}, y_{n}^{*}\right) \times$ $T\left(x_{n}^{*}, y_{n}^{*}\right)$ such that $\hat{d}\left(x_{n}, x_{n}^{*}\right) \leqslant \hat{d}\left(x_{n}, S\left(x_{n}, y_{n}\right)\right), \bar{d}\left(y_{n}, y_{n}^{*}\right) \leqslant \bar{d}\left(y_{n}, T\left(x_{n}, y_{n}\right)\right)$,

$$
\begin{cases}0 \in G\left(p, x_{n}^{*}, y_{n}, u\right)+f\left(p, x_{n}^{*}, y_{n}\right)-f\left(p, u, y_{n}\right)+B^{+}(0, \varepsilon) \hat{e}\left(x_{n}^{*}\right), & \forall u \in S\left(x_{n}^{*}, y_{n}^{*}\right), \\ 0 \in F\left(p, y_{n}^{*}, x_{n}, v\right)+g\left(p, x_{n}, y_{n}^{*}\right)-g\left(p, x_{n}, v\right)+B^{+}(0, \varepsilon) \bar{e}\left(y_{n}^{*}\right), & \forall v \in T\left(x_{n}^{*}, y_{n}^{*}\right) .\end{cases}
$$


Since $S$ is u.s.c. and closed-valued, $S$ is closed and so $x^{*} \in S\left(x^{*}, y^{*}\right)$. Since $T$ is u.s.c. and compactvalued, there exist a subsequence $\left\{y_{n_{k}}\right\}$ of $\left\{y_{n}\right\}$ and $\bar{y} \in T\left(x^{*}, y^{*}\right)$ such that $y_{n_{k}} \rightarrow \bar{y}$ as $k \rightarrow \infty$. It follows that, for each $k \in \mathbf{N}$,

$$
0 \in G\left(p, x_{n_{k}}^{*}, y_{n_{k}}, u\right)+f\left(p, x_{n_{k}}^{*}, y_{n_{k}}\right)-f\left(p, u, y_{n_{k}}\right)+B^{+}(0, \varepsilon) \hat{e}\left(x_{n_{k}}^{*}\right), \quad \forall u \in S\left(x_{n_{k}}^{*}, y_{n_{k}}^{*}\right) .
$$

For each $u \in S\left(x^{*}, y^{*}\right)$, since $S$ is l.s.c., there exists a sequence $\left\{u_{n_{k}}\right\}$ with $u_{n_{k}} \in S\left(x_{n_{k}}^{*}, y_{n_{k}}^{*}\right)$ such that $u_{k} \rightarrow u$ as $k \rightarrow \infty$, and so

$$
0 \in G\left(p, x_{n_{k}}^{*}, y_{n_{k}}, u_{k}\right)+f\left(p, x_{n_{k}}^{*}, y_{n_{k}}\right)-f\left(p, u_{k}, y_{n_{k}}\right)+B^{+}(0, \varepsilon) \hat{e}\left(x_{n_{k}}^{*}\right) .
$$

Next, for each $k \in \mathbf{N}$, we get the following relation associated with (3.10)

$$
0 \in F\left(p, y_{n_{k}}^{*}, x_{n_{k}}, v\right)+g\left(p, x_{n_{k}}, y_{n_{k}}^{*}\right)-g\left(p, x_{n_{k}}, v\right)+B^{+}(0, \varepsilon) \bar{e}\left(y_{n_{k}}^{*}\right), \quad \forall v \in T\left(x_{n_{k}}^{*}, y_{n_{k}}^{*}\right) .
$$

Since $T$ is u.s.c. and closed-valued, $T$ is closed and so $y^{*} \in T\left(x^{*}, y^{*}\right)$. Since $S$ is u.s.c. and compact-valued, there exist a subsequence of $\left\{x_{n_{k}}\right\}$, denoted still by $\left\{x_{n_{k}}\right\}$, and $\hat{x} \in S\left(x^{*}, y^{*}\right)$ such that $x_{n_{k}} \rightarrow \hat{x}$ as $k \rightarrow \infty$. Moreover, for each $v \in T\left(x^{*}, y^{*}\right)$, since $T$ is l.s.c., there exists a sequence $\left\{v_{k}\right\}$ with $v_{k} \in T\left(x_{n_{k}}^{*}, y_{n_{k}}^{*}\right)$ such that $v_{\mathrm{k}} \rightarrow v$ as $\mathrm{k} \rightarrow \infty$, and so

$$
0 \in F\left(p, y_{n_{k}}^{*}, x_{n_{k}}, v_{k}\right)+g\left(p, x_{n_{k}}, y_{n_{k}}^{*}\right)-g\left(p, x_{n_{k}}, v_{k}\right)+B^{+}(0, \varepsilon) \bar{e}\left(y_{n_{k}}^{*}\right) .
$$

So, it follows from (3.11) and (3.12) that there exist two sequences $\left\{\hat{\gamma}_{k}\right\}$ and $\left\{\bar{\gamma}_{k}\right\}$ in $B^{+}(0, \varepsilon)$ such that for all $k \in \mathbf{N}$

$$
\left\{\begin{array}{l}
0 \in G\left(p, x_{n_{k}}^{*}, y_{n_{k}}, u_{k}\right)+f\left(p, x_{n_{k}}^{*}, y_{n_{k}}\right)-f\left(p, u_{k}, y_{n_{k}}\right)+\hat{\gamma}_{k} \hat{e}\left(x_{n_{k}}^{*}\right), \\
0 \in F\left(p, y_{n_{k}}^{*}, x_{n_{k}}, v_{k}\right)+g\left(p, x_{n_{k}}, y_{n_{k}}^{*}\right)-g\left(p, x_{n_{k}}, v_{k}\right)+\bar{\gamma}_{k} \bar{e}\left(y_{n_{k}}^{*}\right) .
\end{array}\right.
$$

Observe that $\mathrm{B}^{+}(0, \varepsilon)=[0, \varepsilon] \subseteq \mathbf{R}$ is compact. We may assume that $\hat{\gamma}_{k} \rightarrow \hat{\gamma} \in \mathrm{B}^{+}(0, \varepsilon)$ and $\bar{\gamma}_{k} \rightarrow \bar{\gamma} \in$ $\mathrm{B}^{+}(0, \varepsilon)$ as $\mathrm{k} \rightarrow \infty$. Since multivalued mappings $(x, y, u) \mapsto \mathrm{G}(\mathrm{p}, x, y, u)$ and $(y, x, v) \mapsto F(p, y, x, v)$ are closed and single-valued mappings $(u, y) \mapsto f(p, u, y)$ and $(x, v) \mapsto g(p, x, v)$ are continuous, we obtain from (3.13) that

$$
\begin{cases}0 \in \mathrm{G}\left(\mathrm{p}, \mathrm{x}^{*}, \bar{y}, \mathrm{u}\right)+\mathrm{f}\left(\mathrm{p}, \mathrm{x}^{*}, \bar{y}\right)-\mathrm{f}(\mathrm{p}, \mathrm{u}, \bar{y})+\hat{\gamma} \hat{e}\left(x^{*}\right), & \forall \mathrm{u} \in \mathrm{S}\left(\mathrm{x}^{*}, \mathrm{y}^{*}\right), \\ 0 \in \mathrm{F}\left(\mathrm{p}, \mathrm{y}^{*}, \hat{x}, v\right)+\mathrm{g}\left(\mathrm{p}, \hat{x}, \mathrm{y}^{*}\right)-\mathrm{g}(\mathrm{p}, \hat{x}, v)+\bar{\gamma} \bar{e}\left(\mathrm{y}^{*}\right), & \forall v \in \mathrm{T}\left(\mathrm{x}^{*}, \mathrm{y}^{*}\right),\end{cases}
$$

which immediately yields

$$
\begin{cases}0 \in G\left(p, x^{*}, \bar{y}, u\right)+f\left(p, x^{*}, \bar{y}\right)-f(p, u, \bar{y})+B^{+}(0, \varepsilon) \hat{e}\left(x^{*}\right), & \forall u \in S\left(x^{*}, y^{*}\right), \\ 0 \in F\left(p, y^{*}, \hat{x}, v\right)+g\left(p, \hat{x}, y^{*}\right)-g(p, \hat{x}, v)+B^{+}(0, \varepsilon) \bar{e}\left(y^{*}\right), & \forall v \in T\left(x^{*}, y^{*}\right) .\end{cases}
$$

From condition (iv) and the convergence of $\left(x_{n_{k}}, y_{n_{k}}\right)\left(\in S\left(x_{n_{k}}^{*}, y_{n_{k}}^{*}\right) \times T\left(x_{n_{k}}^{*}, y_{n_{k}}^{*}\right), k \in N\right)$ to $(\hat{x}, \bar{y})$, it follows that $\hat{d}\left(x_{n_{k}}, S\left(x_{n_{k}}, y_{n_{k}}\right)\right) \rightarrow 0$ and $\bar{d}\left(y_{n_{k}}, T\left(x_{n_{k}}, y_{n_{k}}\right)\right) \rightarrow 0$ as $k \rightarrow \infty$. Thus,

$$
\hat{d}\left(\hat{x}, x^{*}\right)=\lim _{k \rightarrow \infty} \hat{d}\left(x_{n_{k}}, x_{n_{k}}^{*}\right) \leqslant \lim _{k \rightarrow \infty} \hat{d}\left(x_{n_{k}}, S\left(x_{n_{k}}, y_{n_{k}}\right)\right)=0,
$$

and

$$
\overline{\mathrm{d}}\left(\overline{\mathrm{y}}, \mathrm{y}^{*}\right)=\lim _{k \rightarrow \infty} \overline{\mathrm{d}}\left(\mathrm{y}_{n_{k}}, y_{n_{k}}^{*}\right) \leqslant \lim _{k \rightarrow \infty} d\left(y_{n_{k}}, T\left(x_{n_{k}}, y_{n_{k}}\right)\right)=0 .
$$

So, we get $\hat{x}=x^{*}$ and $\bar{y}=y^{*}$. Consequently, from (3.14) we have

$$
\begin{cases}0 \in G\left(p, x^{*}, y^{*}, u\right)+f\left(p, x^{*}, y^{*}\right)-f\left(p, u, y^{*}\right)+B^{+}(0, \varepsilon) \hat{e}\left(x^{*}\right), & \forall u \in S\left(x^{*}, y^{*}\right), \\ 0 \in F\left(p, y^{*}, x^{*}, v\right)+g\left(p, x^{*}, y^{*}\right)-g\left(p, x^{*}, v\right)+B^{+}(0, \varepsilon) \bar{e}\left(y^{*}\right), & \forall v \in T\left(x^{*}, y^{*}\right) .\end{cases}
$$

That is, $\left(x^{*}, y^{*}\right) \in A$, which hence implies clA $\subseteq A$. Therefore, $A=\operatorname{cl} A$. 
Proposition 3.6. Assume that

(i) $\mathrm{P}$ is finite-dimensional;

(ii) $\mathrm{S}$ and $\mathrm{T}$ are continuous and compact-valued;

(iii) single-valued mappings $\mathrm{f}$ and $\mathrm{g}$ are continuous;

(iv) multivalued mappings $\mathrm{G}$ and $\mathrm{F}$ are closed;

(v) for every $\mathrm{p} \in \mathrm{P}$, there exists $\Omega_{\mathfrak{p}}(\delta, \varepsilon)$ such that for each convergent sequence $\left\{\left(x_{n}^{*}, y_{n}^{*}\right)\right\} \subseteq \Omega_{p}(\delta, \varepsilon)$, the convergence of $\left(x_{n}, y_{n}\right)\left(\in S\left(x_{n}^{*}, y_{n}^{*}\right) \times T\left(x_{n}^{*}, y_{n}^{*}\right), n \in N\right)$ implies $\hat{d}\left(x_{n}, S\left(x_{n}, y_{n}\right)\right) \rightarrow 0$ and

$$
\overline{\mathrm{d}}\left(\mathrm{y}_{n}, \mathrm{~T}\left(\mathrm{x}_{\mathrm{n}}, \mathrm{y}_{\mathrm{n}}\right)\right) \rightarrow 0 .
$$

Then, for each $\mathrm{p} \in \mathrm{P}, \Omega_{\mathrm{p}}(\delta, \varepsilon)$ is a closed subset of $\mathrm{C} \times \mathrm{D}$.

Proof. Take any $p \in P$ and any $\delta, \varepsilon>0$ and let $(p, \delta, \varepsilon)$ be fixed. If $\left(x^{*}, y^{*}\right) \in \operatorname{cl}\left(\Omega_{p}(\delta, \varepsilon)\right)$, then there exists a sequence $\left\{\left(x_{n}^{*}, y_{\mathfrak{n}}^{*}\right)\right\}$ in $\Omega_{\mathfrak{p}}(\delta, \varepsilon)$ such that $\left(x_{\mathfrak{n}}^{*}, y_{\mathfrak{n}}^{*}\right) \rightarrow\left(x^{*}, y^{*}\right)$ (i.e., $x_{\mathfrak{n}}^{*} \rightarrow x^{*}$ and $\left.y_{\mathfrak{n}}^{*} \rightarrow y^{*}\right)$ as $n \rightarrow \infty$. It follows that, for each $n \in \mathbf{N},\left(x_{n}^{*}, y_{n}^{*}\right) \in S\left(x_{n}^{*}, y_{n}^{*}\right) \times T\left(x_{n}^{*}, y_{n}^{*}\right)$ and there exist $p_{n} \in B(p, \delta)$ and $\left(x_{n}, y_{n}\right) \in S\left(x_{n}^{*}, y_{n}^{*}\right) \times T\left(x_{n}^{*}, y_{n}^{*}\right)$ such that $\hat{d}\left(x_{n}, x_{n}^{*}\right) \leqslant \hat{d}\left(x_{n}, S\left(x_{n}, y_{n}\right)\right), \bar{d}\left(y_{n}, y_{n}^{*}\right) \leqslant \bar{d}\left(y_{n}, T\left(x_{n}, y_{n}\right)\right)$,

$$
\begin{cases}0 \in G\left(p_{n}, x_{n}^{*}, y_{n}, u\right)+f\left(p_{n}, x_{n}^{*}, y_{n}\right)-f\left(p_{n}, u, y_{n}\right)+B^{+}(0, \varepsilon) \hat{e}\left(x_{n}^{*}\right), & \forall u \in S\left(x_{n}^{*}, y_{n}^{*}\right), \\ 0 \in F\left(p_{n}, y_{n}^{*}, x_{n}, v\right)+g\left(p_{n}, x_{n}, y_{n}^{*}\right)-g\left(p_{n}, x_{n}, v\right)+B^{+}(0, \varepsilon) \bar{e}\left(y_{n}^{*}\right), & \forall v \in T\left(x_{n}^{*}, y_{n}^{*}\right) .\end{cases}
$$

Note that $P$ is finite-dimensional. We may assume that $p_{n} \rightarrow \tilde{p} \in B(p, \delta)$. Then, by the similar arguments to those in the second part of the proof of Proposition 3.5, we can show that $\left(x^{*}, y^{*}\right) \in S\left(x^{*}, y^{*}\right) \times T\left(x^{*}, y^{*}\right)$ and

$$
\begin{cases}0 \in \mathrm{G}\left(\tilde{\mathrm{p}}, x^{*}, \mathrm{y}^{*}, u\right)+\mathrm{f}\left(\tilde{\mathrm{p}}, x^{*}, y^{*}\right)-\mathrm{f}\left(\tilde{\mathrm{p}}, \mathrm{u}, \mathrm{y}^{*}\right)+\mathrm{B}^{+}(0, \varepsilon) \hat{\mathrm{e}}\left(x^{*}\right), & \forall \mathrm{u} \in \mathrm{S}\left(\mathrm{x}^{*}, \mathrm{y}^{*}\right), \\ 0 \in \mathrm{F}\left(\tilde{\mathrm{p}}, \mathrm{y}^{*}, x^{*}, v\right)+\mathrm{g}\left(\tilde{\mathrm{p}}, x^{*}, \mathrm{y}^{*}\right)-\mathrm{g}\left(\tilde{\mathrm{p}}, x^{*}, v\right)+\mathrm{B}^{+}(0, \varepsilon) \bar{e}\left(\mathrm{y}^{*}\right), & \forall v \in \mathrm{T}\left(x^{*}, y^{*}\right) .\end{cases}
$$

That is, $\left(x^{*}, y^{*}\right) \in \Omega_{\mathfrak{p}}(\delta, \varepsilon)$, which hence implies $\operatorname{cl}\left(\Omega_{\mathfrak{p}}(\delta, \varepsilon)\right) \subseteq \Omega_{\mathfrak{p}}(\delta, \varepsilon)$. Therefore, $\Omega_{\mathfrak{p}}(\delta, \varepsilon)=\operatorname{cl}\left(\Omega_{\mathfrak{p}}(\delta, \varepsilon)\right)$. This completes the proof.

Theorem 3.7. Let $\mathrm{X}$ and $\mathrm{Y}$ be complete. Assume that

(i) S and T are continuous and compact-valued;

(ii) single-valued mappings $\mathrm{f}$ and $\mathrm{g}$ are continuous;

(iii) multivalued mappings $\mathrm{G}$ and $\mathrm{F}$ are closed;

(iv) for every $p \in P$, there exists $\Omega_{p}(\delta, \varepsilon)$ such that for each convergent sequence $\left\{\left(x_{n}^{*}, y_{n}^{*}\right)\right\} \subseteq \Omega_{p}(\delta, \varepsilon)$, the convergence of $\left(x_{n}, y_{n}\right)\left(\in S\left(x_{n}^{*}, y_{n}^{*}\right) \times T\left(x_{n}^{*}, y_{n}^{*}\right), n \in N\right)$ implies $\hat{d}\left(x_{n}, S\left(x_{n}, y_{n}\right)\right) \rightarrow 0$ and

$$
\overline{\mathrm{d}}\left(\mathrm{y}_{n}, \mathrm{~T}\left(\mathrm{x}_{\mathrm{n}}, \mathrm{y}_{\mathrm{n}}\right)\right) \rightarrow 0 .
$$

Then (SGMQVIP) is well-posed if and only if for every $\mathrm{p} \in \mathrm{P}$,

$$
\Omega_{\mathfrak{p}}(\delta, \varepsilon) \neq \emptyset, \quad \forall \delta, \varepsilon>0, \quad \text { and } \operatorname{diam}\left(\Omega_{\mathfrak{p}}(\delta, \varepsilon)\right) \rightarrow 0 \text { as }(\delta, \varepsilon) \rightarrow(0,0) .
$$

Proof. Suppose that (SGMQVIP) is well-posed. Then, for every $\mathrm{p} \in \mathrm{P},(\mathrm{SGMQVIP})_{\mathrm{p}}$ has a unique solution $\left(x_{p}, y_{p}\right)$, and so $\Omega_{p}(\delta, \varepsilon) \neq \emptyset$ since $\left(x_{p}, y_{p}\right) \in S_{p} \subseteq \Omega_{p}(\delta, \varepsilon)$ for all $\delta, \varepsilon>0$.

Now we shall show that

$$
\operatorname{diam}\left(\Omega_{\mathfrak{p}}(\delta, \varepsilon)\right) \rightarrow 0 \text { as }(\delta, \varepsilon) \rightarrow(0,0) .
$$

If not, then there exist $r>0$, sequences $\left\{\delta_{n}\right\}$ and $\left\{\varepsilon_{n}\right\}$ of positive real numbers with $\left(\delta_{n}, \varepsilon_{n}\right) \rightarrow(0,0)$ as $n \rightarrow \infty$ and sequences $\left\{\left(x_{n}^{1 *}, y_{n}^{1 *}\right)\right\}$ and $\left\{\left(x_{n}^{2 *}, y_{n}^{2 *}\right)\right\}$ with $\left(x_{n}^{1 *}, y_{n}^{1 *}\right),\left(x_{n}^{2 *}, y_{n}^{2 *}\right) \in \Omega_{p}\left(\delta_{n}, \varepsilon_{n}\right)$ for each $n \in \mathbf{N}$ such that

$$
r<d\left(\left(x_{n}^{1 *}, y_{n}^{1 *}\right),\left(x_{n}^{2 *}, y_{n}^{2 *}\right)\right)=\sqrt{\left(\hat{d}\left(x_{n}^{1 *}, x_{n}^{2 *}\right)\right)^{2}+\left(\bar{d}\left(y_{n}^{1 *}, y_{n}^{2 *}\right)\right)^{2}}, \quad n \in \mathbf{N} .
$$


For each $n \in \mathbf{N}$ and $i=1,2$, since $\left(x_{n}^{i *}, y_{n}^{i *}\right) \in \Omega_{p}\left(\delta_{n}, \varepsilon_{n}\right)$, we know that

$$
\left(x_{n}^{i *}, y_{n}^{i *}\right) \in S\left(x_{n}^{i *}, y_{n}^{i *}\right) \times T\left(x_{n}^{i *}, y_{n}^{i *}\right),
$$

and there exist $p_{n}^{i} \in B\left(p, \delta_{n}\right)$ and $\left(x_{n}^{i}, y_{n}^{i}\right) \in S\left(x_{n}^{i *}, y_{n}^{i *}\right) \times T\left(x_{n}^{i *}, y_{n}^{i *}\right)$ such that

$$
\begin{gathered}
\hat{\mathrm{d}}\left(x_{n}^{i}, x_{n}^{i *}\right) \leqslant \hat{\mathrm{d}}\left(x_{n}^{i}, S\left(x_{n}^{i}, y_{n}^{i}\right)\right), \overline{\mathrm{d}}\left(y_{n}^{i}, y_{n}^{i *}\right) \leqslant \bar{d}\left(y_{n}^{i}, T\left(x_{n}^{i}, y_{n}^{i}\right)\right), \\
\begin{cases}0 \in G\left(p_{n}^{i}, x_{n}^{i *}, y_{n}^{i}, u\right)+f\left(p_{n}^{i}, x_{n}^{i *}, y_{n}^{i}\right)-f\left(p_{n}^{i}, u, y_{n}^{i}\right)+B^{+}\left(0, \varepsilon_{n}\right) \hat{e}\left(x_{n}^{i *}\right), & \forall u \in S\left(x_{n}^{i *}, y_{n}^{i *}\right), \\
0 \in F\left(p_{n}^{i}, y_{n}^{i *}, x_{n}^{i}, v\right)+g\left(p_{n}^{i}, x_{n}^{i}, y_{n}^{i *}\right)-g\left(p_{n}^{i}, x_{n}^{i}, v\right)+B^{+}\left(0, \varepsilon_{n}\right) \bar{e}\left(y_{n}^{i *}\right), & \forall v \in T\left(x_{n}^{i *}, y_{n}^{i *}\right) .\end{cases}
\end{gathered}
$$

Clearly $p_{n}^{1} \rightarrow p$ and $p_{n}^{2} \rightarrow p$ as $n \rightarrow \infty$. Hence $\left\{\left(x_{n}^{1 *}, y_{n}^{1 *}\right)\right\}$ and $\left\{\left(x_{n}^{2 *}, y_{n}^{2 *}\right)\right\}$ are approximating solution sequences for (SGMQVIP) $)_{p}$ corresponding to $\left\{p_{n}^{1}\right\}$ and $\left\{p_{n}^{2}\right\}$, respectively. Then, by the well-posedness of (SGMQVIP), they have to converge to the unique solution $\left(x_{p}, y_{p}\right)$ of $(S G M Q V I P)_{p}$, a contradiction to (3.17). Thus (3.16) holds.

Conversely, suppose that condition (3.15) holds. Take any $p \in P$ and let $p$ be fixed. Let $\left\{p_{n}\right\}$ be any sequence in $\mathrm{P}$ with $\mathrm{p}_{\mathrm{n}} \rightarrow \mathrm{p}$ as $\mathrm{n} \rightarrow \infty$. If $\left\{\left(x_{n}^{*}, y_{n}^{*}\right)\right\}$ is an approximating solution sequence for $(\text { SGMQVIP })_{p}$ corresponding to $\left\{p_{n}\right\}$, then for each $n \in N,\left(x_{n}^{*}, y_{n}^{*}\right) \in S\left(x_{n}^{*}, y_{n}^{*}\right) \times T\left(x_{n}^{*}, y_{n}^{*}\right)$, and there exist $\left(x_{n}, y_{n}\right) \in S\left(x_{n}^{*}, y_{n}^{*}\right) \times T\left(x_{n}^{*}, y_{n}^{*}\right)$ and a sequence $\varepsilon_{n}>0$ with $\varepsilon_{n} \rightarrow 0$ such that

$$
\begin{gathered}
\hat{d}\left(x_{n}, x_{n}^{*}\right) \leqslant \hat{d}\left(x_{n}, S\left(x_{n}, y_{n}\right)\right), \bar{d}\left(y_{n}, y_{n}^{*}\right) \leqslant \bar{d}\left(y_{n}, T\left(x_{n}, y_{n}\right)\right), \\
\begin{cases}0 \in G\left(p_{n}, x_{n}^{*}, y_{n}, u\right)+f\left(p_{n}, x_{n}^{*}, y_{n}\right)-f\left(p_{n}, u, y_{n}\right)+B^{+}\left(0, \varepsilon_{n}\right) \hat{e}\left(x_{n}^{*}\right), & \forall u \in S\left(x_{n}^{*}, y_{n}^{*}\right), \\
0 \in F\left(p_{n}, y_{n}^{*}, x_{n}, v\right)+g\left(p_{n}, x_{n}, y_{n}^{*}\right)-g\left(p_{n}, x_{n}, v\right)+B^{+}\left(0, \varepsilon_{n}\right) \bar{e}\left(y_{n}^{*}\right), & \forall v \in T\left(x_{n}^{*}, y_{n}^{*}\right) .\end{cases}
\end{gathered}
$$

For each $n \in \mathbf{N}$, let $\delta_{n}=d_{0}\left(p_{n}, p\right)$. Then, $p_{n} \in B\left(p, \delta_{n}\right)$ and $\left(x_{n}^{*}, y_{n}^{*}\right) \in \Omega_{p}\left(\delta_{n}, \varepsilon_{n}\right)$ for each $n \in \mathbf{N}$, and $\delta_{n} \rightarrow 0$ as $n \rightarrow \infty$. It follows from (3.15) that $\left\{\left(x_{n}^{*}, y_{n}^{*}\right)\right\}$ is a Cauchy sequence and so it converges to a point $\left(x^{*}, y^{*}\right) \in C \times D$. Then, by the similar arguments to those in the second part of the proof of Proposition 3.5, we can show that $\left(x^{*}, y^{*}\right) \in S\left(x^{*}, y^{*}\right) \times T\left(x^{*}, y^{*}\right)$ and

$$
\begin{cases}0 \in G\left(p, x^{*}, y^{*}, u\right)+f\left(p, x^{*}, y^{*}\right)-f\left(p, u, y^{*}\right), & \forall u \in S\left(x^{*}, y^{*}\right), \\ 0 \in F\left(p, y^{*}, x^{*}, v\right)+g\left(p, x^{*}, y^{*}\right)-g\left(p, x^{*}, v\right), & \forall v \in T\left(x^{*}, y^{*}\right) .\end{cases}
$$

Thus $\left(x^{*}, y^{*}\right)$ is a solution of (SGMQVIP $)_{p}$.

To complete the proof, it is sufficient to prove that (SGMQVIP) $)_{p}$ has a unique solution. If (SGMQVIP) $p$ has two distinct solutions $\left(x^{1}, y^{1}\right)$ and $\left(x^{2}, y^{2}\right)$, it is easy to see that $\left(x^{1}, y^{1}\right),\left(x^{2}, y^{2}\right) \in \Omega_{p}(\delta, \varepsilon)$ for all $\delta, \varepsilon>0$. It follows that

$$
0<\mathrm{d}\left(\left(x^{1}, \mathrm{y}^{1}\right),\left(x^{2}, \mathrm{y}^{2}\right)\right) \leqslant \operatorname{diam}\left(\Omega_{\mathrm{p}}(\delta, \varepsilon)\right), \quad \forall \delta, \varepsilon>0,
$$

a contradiction to (3.15). Therefore, (SGMQVIP) $)_{p}$ has a unique solution. This completes the proof.

Theorem 3.8. Let $\mathrm{X}$ and $\mathrm{Y}$ be complete. Assume that

(i) $\mathrm{P}$ is finite-dimensional;

(ii) $\mathrm{S}$ and $\mathrm{T}$ are continuous and compact-valued;

(iii) single-valued mappings $f$ and $g$ are continuous;

(iv) multivalued mappings $\mathrm{G}$ and $\mathrm{F}$ are closed;

(v) for every $\mathrm{p} \in \mathrm{P}$, there exists $\Omega_{\mathrm{p}}(\delta, \varepsilon)$ such that for each convergent sequence $\left\{\left(x_{n}^{*}, y_{n}^{*}\right)\right\} \subseteq \Omega_{\mathrm{p}}(\delta, \varepsilon)$, the convergence of $\left(x_{n}, y_{n}\right)\left(\in S\left(x_{n}^{*}, y_{n}^{*}\right) \times T\left(x_{n}^{*}, y_{n}^{*}\right), n \in N\right)$ implies

$$
\left\{\begin{array}{l}
\hat{d}\left(x_{n}, S\left(x_{n}, y_{n}\right)\right) \rightarrow 0 \\
\bar{d}\left(y_{n}, T\left(x_{n}, y_{n}\right)\right) \rightarrow 0 .
\end{array}\right.
$$


Then (SGMQVIP) is well-posed in the generalized sense if and only if for every $\mathrm{p} \in \mathrm{P}$,

$$
\Omega_{\mathfrak{p}}(\delta, \varepsilon) \neq \emptyset, \quad \forall \delta, \varepsilon>0, \quad \text { and } \mu\left(\Omega_{\mathfrak{p}}(\delta, \varepsilon)\right) \rightarrow 0 \text { as }(\delta, \varepsilon) \rightarrow(0,0) .
$$

Proof. Suppose that (SGMQVIP) is well-posed in the generalized sense. Take any $p \in P$ and let $p$ be fixed. Then $S_{p}$ is nonempty. Now we show that $S_{p}$ is compact. Indeed, let $\left\{\left(x_{n}^{*}, y_{n}^{*}\right)\right\}$ be any sequence in $S_{p}$. Then $\left\{\left(x_{n}^{*}, y_{n}^{*}\right)\right\}$ is an approximating solution sequence for (SGMQVIP $)_{p}$. By the well-posedness in the generalized sense of (SGMQVIP), $\left\{\left(x_{n}^{*}, y_{n}^{*}\right)\right\}$ has a subsequence which converges to some point of $S_{p}$. Thus $S_{p}$ is compact. Clearly, for each $\delta, \varepsilon>0, S_{p} \subseteq \Omega_{p}(\delta, \varepsilon)$, and so $\Omega_{p}(\delta, \varepsilon) \neq \emptyset$.

Now we shall show that

$$
\mu\left(\Omega_{\mathfrak{p}}(\delta, \varepsilon)\right) \rightarrow 0 \quad \text { as } \quad(\delta, \varepsilon) \rightarrow(0,0) .
$$

Observe that for every $\delta, \varepsilon>0$,

$$
\mathcal{H}\left(\Omega_{\mathfrak{p}}(\delta, \varepsilon), S_{p}\right)=\max \left\{e\left(\Omega_{p}(\delta, \varepsilon), S_{p}\right), e\left(S_{p}, \Omega_{p}(\delta, \varepsilon)\right)\right\}=e\left(\Omega_{p}(\delta, \varepsilon), S_{p}\right) .
$$

Taking into account the compactness of $S_{p}$, we get

$$
\mu\left(\Omega_{\mathfrak{p}}(\delta, \varepsilon)\right) \leqslant 2 \mathcal{H}\left(\Omega_{\mathfrak{p}}(\delta, \varepsilon), S_{\mathfrak{p}}\right)+\mu\left(S_{\mathfrak{p}}\right)=2 e\left(\Omega_{\mathfrak{p}}(\delta, \varepsilon), S_{\mathfrak{p}}\right) .
$$

To prove (3.19), it is sufficient to show that

$$
e\left(\Omega_{p}(\delta, \varepsilon), S_{p}\right) \rightarrow 0 \text { as }(\delta, \varepsilon) \rightarrow(0,0) .
$$

As a matter of fact, if (3.20) does not hold, then there exist $r>0$, sequences $\left\{\delta_{n}\right\}$ and $\left\{\varepsilon_{n}\right\}$ of positive real numbers with $\left(\delta_{n}, \varepsilon_{n}\right) \rightarrow(0,0)$ as $n \rightarrow \infty$ and sequence $\left\{\left(x_{n}^{*}, y_{n}^{*}\right)\right\}$ with $\left(x_{n}^{*}, y_{n}^{*}\right) \in \Omega_{p}\left(\delta_{n}, \varepsilon_{n}\right)$ for every $n \in \mathbf{N}$ such that

$$
\left(x_{n}^{*}, y_{n}^{*}\right) \notin S_{p}+B(0, r), \quad \forall n \in N .
$$

For each $n \in \mathbf{N}$, since $\left(x_{n}^{*}, y_{n}^{*}\right) \in \Omega_{p}\left(\delta_{n}, \varepsilon_{n}\right)$, we know that $\left(x_{n}^{*}, y_{n}^{*}\right) \in S\left(x_{n}^{*}, y_{n}^{*}\right) \times T\left(x_{n}^{*}, y_{n}^{*}\right)$, and there exist $p_{n} \in B\left(p, \delta_{n}\right)$ and $\left(x_{n}, y_{n}\right) \in S\left(x_{n}^{*}, y_{n}^{*}\right) \times T\left(x_{n}^{*}, y_{n}^{*}\right)$ such that

$$
\begin{gathered}
\hat{d}\left(x_{n}, x_{n}^{*}\right) \leqslant \hat{d}\left(x_{n}, S\left(x_{n}, y_{n}\right)\right), \bar{d}\left(y_{n}, y_{n}^{*}\right) \leqslant \bar{d}\left(y_{n}, T\left(x_{n}, y_{n}\right)\right), \\
\begin{cases}0 \in G\left(p_{n}, x_{n}^{*}, y_{n}, u\right)+f\left(p_{n}, x_{n}^{*}, y_{n}\right)-f\left(p_{n}, u, y_{n}\right)+B^{+}\left(0, \varepsilon_{n}\right) \hat{e}\left(x_{n}^{*}\right), & \forall u \in S\left(x_{n}^{*}, y_{n}^{*}\right), \\
0 \in F\left(p_{n}, y_{n}^{*}, x_{n}, v\right)+g\left(p_{n}, x_{n}, y_{n}^{*}\right)-g\left(p_{n}, x_{n}, v\right)+B^{+}\left(0, \varepsilon_{n}\right) \bar{e}\left(y_{n}^{*}\right), & \forall v \in T\left(x_{n}^{*}, y_{n}^{*}\right) .\end{cases}
\end{gathered}
$$

Clearly $p_{n} \rightarrow p$ as $n \rightarrow \infty$. Hence $\left\{\left(x_{n}^{*}, y_{n}^{*}\right)\right\}$ is an approximating solution sequence for (SGMQVIP $)_{p}$ corresponding to $\left\{p_{n}\right\}$. Then, by the well-posedness in the generalized sense of (SGMQVIP), $\left\{\left(x_{n}^{*}, y_{n}^{*}\right)\right\}$ has a subsequence $\left\{\left(x_{n_{k}}^{*}, y_{n_{k}}^{*}\right)\right\}$ which converges to some point of $S_{p}$. This contradicts (3.21), and so (3.20) holds.

Conversely, suppose that condition (3.18) holds. Take a fixed $\mathrm{p} \in \mathrm{P}$ arbitrarily. Then, by Propositions 3.4 and 3.6, $\Omega_{p}(\delta, \varepsilon)$ is closed for $\delta, \varepsilon>0$ small enough and $S_{p}=\bigcap_{\delta>0, \varepsilon>0} \Omega_{p}(\delta, \varepsilon)$. Since $\mu\left(\Omega_{p}(\delta, \varepsilon)\right) \rightarrow 0$ as $(\delta, \varepsilon) \rightarrow(0,0)$, by the Kuratowski theorem [14], $S_{p}$ is nonempty and compact and

$$
e\left(\Omega_{\mathfrak{p}}(\delta, \varepsilon), S_{\mathfrak{p}}\right) \rightarrow 0 \text { as }(\delta, \varepsilon) \rightarrow(0,0) .
$$

Let $\left\{p_{n}\right\}$ be any sequence in $P$ with $p_{n} \rightarrow p$ as $n \rightarrow \infty$. If $\left\{\left(x_{n}^{*}, y_{n}^{*}\right)\right\}$ is an approximating solution sequence for $(S G M Q V I P)_{p}$ corresponding to $\left\{p_{n}\right\}$, then for each $n \in N,\left(x_{n}^{*}, y_{n}^{*}\right) \in S\left(x_{n}^{*}, y_{n}^{*}\right) \times T\left(x_{n}^{*}, y_{n}^{*}\right)$, and there exist $\left(x_{n}, y_{n}\right) \in S\left(x_{n}^{*}, y_{n}^{*}\right) \times T\left(x_{n}^{*}, y_{n}^{*}\right)$ and a sequence $\varepsilon_{n}>0$ with $\varepsilon_{n} \rightarrow 0$ such that

$$
\begin{gathered}
\hat{d}\left(x_{n}, x_{n}^{*}\right) \leqslant \hat{d}\left(x_{n}, S\left(x_{n}, y_{n}\right)\right), \bar{d}\left(y_{n}, y_{n}^{*}\right) \leqslant \bar{d}\left(y_{n}, T\left(x_{n}, y_{n}\right)\right), \\
\begin{cases}0 \in G\left(p_{n}, x_{n}^{*}, y_{n}, u\right)+f\left(p_{n}, x_{n}^{*}, y_{n}\right)-f\left(p_{n}, u, y_{n}\right)+B^{+}\left(0, \varepsilon_{n}\right) \hat{e}\left(x_{n}^{*}\right), & \forall u \in S\left(x_{n}^{*}, y_{n}^{*}\right), \\
0 \in F\left(p_{n}, y_{n}^{*}, x_{n}, v\right)+g\left(p_{n}, x_{n}, y_{n}^{*}\right)-g\left(p_{n}, x_{n}, v\right)+B^{+}\left(0, \varepsilon_{n}\right) \bar{e}\left(y_{n}^{*}\right), & \forall v \in T\left(x_{n}^{*}, y_{n}^{*}\right) .\end{cases}
\end{gathered}
$$


For each $n \in \mathbf{N}$, let $\delta_{n}=d_{0}\left(p_{n}, p\right)$. Then, $p_{n} \in B\left(p, \delta_{n}\right)$ and $\left(x_{n}^{*}, y_{n}^{*}\right) \in \Omega_{p}\left(\delta_{n}, \varepsilon_{n}\right)$ for each $n \in \mathbf{N}$, and $\delta_{n} \rightarrow 0$ as $n \rightarrow \infty$. It follows from (3.22) that $d\left(\left(x_{n}^{*}, y_{n}^{*}\right), S_{p}\right) \leqslant e\left(\Omega_{p}\left(\delta_{n}, \varepsilon_{n}\right), S_{p}\right) \rightarrow 0$ as $n \rightarrow \infty$. Since $S_{p}$ is compact, for each $n \in \mathbf{N}$, there exists $\left(x_{n}^{\prime}, y_{n}^{\prime}\right) \in S_{p}$ such that $d\left(\left(x_{n}^{*}, y_{n}^{*}\right),\left(x_{n}^{\prime}, y_{n}^{\prime}\right)\right)=d\left(\left(x_{n}^{*}, y_{n}^{*}\right), S_{p}\right) \rightarrow 0$ as $n \rightarrow \infty$. Again from the compactness of $S_{p},\left\{\left(x_{n}^{\prime}, y_{n}^{\prime}\right)\right\}$ has a subsequence $\left\{\left(x_{n_{k}}^{\prime}, y_{n_{k}}^{\prime}\right)\right\}$ which converges to a point $\left(x^{*}, y^{*}\right) \in S_{p}$. Hence, the corresponding subsequence $\left\{\left(x_{n_{k}}^{*}, y_{n_{k}}^{*}\right)\right\}$ of $\left\{\left(x_{n}^{*}, y_{n}^{*}\right)\right\}$ converges to $\left(x^{*}, y^{*}\right)$. Therefore, (SGMQVIP) is well-posed in the generalized sense. This completes the proof.

Utilizing the similar reasoning to that in the proof of Theorem 3.8, we have the following characterization by considering the Hauasdorff distance between the solution set and the approximating solution set.

Theorem 3.9. Assume that all the conditions of Theorem 3.8 are satisfied. Then (SGMQVIP) is well-posed in the generalized sense if and only if for every $\mathrm{p} \in \mathrm{P}, \mathrm{S}_{\mathrm{p}}$ is nonempty and compact and $\mathrm{e}\left(\Omega_{\mathrm{p}}(\delta, \varepsilon), S_{\mathrm{p}}\right) \rightarrow 0$ as $(\delta, \varepsilon) \rightarrow(0,0)$.

Proof. By Propositions 3.4 and 3.6, $\Omega_{p}(\delta, \varepsilon)$ is closed for every $\delta, \varepsilon>0$ small enough, and

$$
S_{p}=\bigcap_{\delta>0, \varepsilon>0} \Omega_{\mathfrak{p}}(\delta, \varepsilon)
$$

For the remainder of the proof, using the similar reasoning to that in the proof of Theorem 3.8, we obtain the desired result.

Theorem 3.10. Let $\mathrm{X}$ and $\mathrm{Y}$ be finite-dimensional. Assume that

(i) S and T are continuous and compact-valued;

(ii) single-valued mappings $\mathrm{f}$ and $\mathrm{g}$ are continuous;

(iii) multivalued mappings $\mathrm{G}$ and $\mathrm{F}$ are closed;

(iv) for every $p \in P$, there exists a nonempty and bounded set $\Omega_{p}(\varepsilon, \varepsilon)$ such that for each convergent sequence $\left\{\left(x_{n}^{*}, y_{n}^{*}\right)\right\} \subseteq \Omega_{p}(\varepsilon, \varepsilon)$, the convergence of $\left(x_{n}, y_{n}\right)\left(\in S\left(x_{n}^{*}, y_{n}^{*}\right) \times T\left(x_{n}^{*}, y_{n}^{*}\right), n \in N\right)$ implies $\hat{\mathrm{d}}\left(\mathrm{x}_{\mathrm{n}}, \mathrm{S}\left(\mathrm{x}_{\mathrm{n}}, \mathrm{y}_{\mathrm{n}}\right)\right) \rightarrow 0$ and $\overline{\mathrm{d}}\left(\mathrm{y}_{\mathrm{n}}, \mathrm{T}\left(\mathrm{x}_{\mathrm{n}}, \mathrm{y}_{\mathrm{n}}\right)\right) \rightarrow 0$.

Then $(\mathrm{SGMQVIP})_{\mathrm{p}}$ is well-posed if and only if for every $\mathrm{p} \in \mathrm{P},(\mathrm{SGMQVIP})_{\mathrm{p}}$ has a unique solution.

Proof. The necessity is obvious. For the sufficiency, suppose that (SGMQVIP) $)_{p}$ has a unique solution $\left(x_{p}, y_{p}\right)$ for every $p \in P$. Take a fixed $p \in P$ arbitrarily. Let $\left\{p_{n}\right\}$ be any sequence in $P$ with $p_{n} \rightarrow p$ as $\mathrm{n} \rightarrow \infty$. If $\left\{\left(x_{\mathfrak{n}}^{*}, y_{\mathfrak{n}}^{*}\right)\right\}$ is an approximating solution sequence for (SGMQVIP $)_{\mathbf{p}}$ corresponding to $\left\{\mathrm{p}_{\mathfrak{n}}\right\}$, then for each $n \in N,\left(x_{n}^{*}, y_{n}^{*}\right) \in S\left(x_{n}^{*}, y_{n}^{*}\right) \times T\left(x_{n}^{*}, y_{n}^{*}\right)$, and there exist $\left(x_{n}, y_{n}\right) \in S\left(x_{n}^{*}, y_{n}^{*}\right) \times T\left(x_{n}^{*}, y_{n}^{*}\right)$ and a sequence $\varepsilon_{\mathrm{n}}>0$ with $\varepsilon_{\mathrm{n}} \rightarrow 0$ such that

$$
\begin{gathered}
\hat{d}\left(x_{n}, x_{n}^{*}\right) \leqslant \hat{d}\left(x_{n}, S\left(x_{n}, y_{n}\right)\right), \bar{d}\left(y_{n}, y_{n}^{*}\right) \leqslant \bar{d}\left(y_{n}, T\left(x_{n}, y_{n}\right)\right), \\
\begin{cases}0 \in G\left(p_{n}, x_{n}^{*}, y_{n}, u\right)+f\left(p_{n}, x_{n}^{*}, y_{n}\right)-f\left(p_{n}, u, y_{n}\right)+B^{+}\left(0, \varepsilon_{n}\right) \hat{e}\left(x_{n}^{*}\right), & \forall u \in S\left(x_{n}^{*}, y_{n}^{*}\right), \\
0 \in F\left(p_{n}, y_{n}^{*}, x_{n}, v\right)+g\left(p_{n}, x_{n}, y_{n}^{*}\right)-g\left(p_{n}, x_{n}, v\right)+B^{+}\left(0, \varepsilon_{n}\right) \bar{e}\left(y_{n}^{*}\right), & \forall v \in T\left(x_{n}^{*}, y_{n}^{*}\right) .\end{cases}
\end{gathered}
$$

For each $n \in \mathbf{N}$, let $\delta_{n}=d_{0}\left(p_{n}, p\right)$. Then, $p_{n} \in B\left(p, \delta_{n}\right)$ and $\left(x_{n}^{*}, y_{n}^{*}\right) \in \Omega_{p}\left(\delta_{n}, \varepsilon_{n}\right)$ for each $n \in \mathbf{N}$, and $\delta_{n} \rightarrow 0$ as $n \rightarrow \infty$. Let $\varepsilon>0$ be such that $\Omega_{p}(\varepsilon, \varepsilon)$ is a nonempty and bounded set satisfying condition (iv). Then there exists some $n_{0} \in \mathbf{N}$ such that $\left(x_{n}^{*}, y_{n}^{*}\right) \in \Omega_{p}\left(\delta_{n}, \varepsilon_{n}\right) \subseteq \Omega_{p}(\varepsilon, \varepsilon)$ for all $n \geqslant n_{0}$. Thus $\left\{\left(x_{n}^{*}, y_{n}^{*}\right)\right\}$ is bounded. Let $\left\{\left(x_{n_{k}}^{*}, y_{n_{k}}^{*}\right)\right\}$ be any subsequence of $\left\{\left(x_{n}^{*}, y_{n}^{*}\right)\right\}$ such that $\left(x_{n_{k}}^{*}, y_{n_{k}}^{*}\right) \rightarrow\left(x^{*}, y^{*}\right)$ as $k \rightarrow \infty$. Then, by the similar arguments to those in the second part of the proof of Proposition 3.5, we can show that $\left(x^{*}, y^{*}\right) \in S\left(x^{*}, y^{*}\right) \times T\left(x^{*}, y^{*}\right)$ and

$$
\begin{cases}0 \in G\left(p, x^{*}, y^{*}, u\right)+f\left(p, x^{*}, y^{*}\right)-f\left(p, u, y^{*}\right), & \forall u \in S\left(x^{*}, y^{*}\right), \\ 0 \in F\left(p, y^{*}, x^{*}, v\right)+g\left(p, x^{*}, y^{*}\right)-g\left(p, x^{*}, v\right), & \forall v \in T\left(x^{*}, y^{*}\right) .\end{cases}
$$


Thus $\left(x^{*}, y^{*}\right)$ is a solution of (SGMQVIP $)_{p}$. By the solution uniqueness to (SGMQVIP) $)_{p}$, we have $\left(x^{*}, y^{*}\right)=\left(x_{p}, y_{p}\right)$. Thus, the whole sequence $\left\{\left(x_{n}^{*}, y_{n}^{*}\right)\right\}$ converges to $\left(x_{p}, y_{p}\right)$ and so (SGMQVIP) is well-posed.

Theorem 3.11. Let $\mathrm{X}$ and $\mathrm{Y}$ be finite-dimensional. Assume that

(i) S and T are continuous and compact-valued;

(ii) single-valued mappings $\mathrm{f}$ and $\mathrm{g}$ are continuous;

(iii) multivalued mappings $\mathrm{G}$ and $\mathrm{F}$ are closed;

(iv) for every $p \in P$, there exists a nonempty and bounded set $\Omega_{p}(\varepsilon, \varepsilon)$ such that for each convergent sequence $\left\{\left(x_{n}^{*}, y_{n}^{*}\right)\right\} \subseteq \Omega_{p}(\varepsilon, \varepsilon)$, the convergence of $\left(x_{n}, y_{n}\right)\left(\in S\left(x_{n}^{*}, y_{n}^{*}\right) \times T\left(x_{n}^{*}, y_{n}^{*}\right), n \in N\right)$ implies $\hat{\mathrm{d}}\left(x_{n}, S\left(x_{n}, y_{n}\right)\right) \rightarrow 0$ and $\overline{\mathrm{d}}\left(y_{n}, T\left(x_{n}, y_{n}\right)\right) \rightarrow 0$.

Then (SGMQVIP) $)_{p}$ is well-posed in the generalized sense if and only if for every $p \in P,(\text { SGMQVIP })_{p}$ has a nonempty solution set $\mathrm{S}_{\mathrm{p}}$.

Proof. The necessity is obvious. For the sufficiency, suppose that (SGMQVIP $)_{p}$ has a nonempty solution set $S_{p}$ for every $p \in P$. Take a fixed $p \in P$ arbitrarily. Let $\left\{p_{n}\right\}$ be any sequence in $P$ with $p_{n} \rightarrow p$ as $\mathrm{n} \rightarrow \infty$. If $\left\{\left(x_{n}^{*}, y_{n}^{*}\right)\right\}$ is an approximating solution sequence for (SGMQVIP $)_{p}$ corresponding to $\left\{p_{n}\right\}$, then for each $n \in \mathbf{N},\left(x_{n}^{*}, y_{n}^{*}\right) \in S\left(x_{n}^{*}, y_{n}^{*}\right) \times T\left(x_{n}^{*}, y_{n}^{*}\right)$, and there exist $\left(x_{n}, y_{n}\right) \in S\left(x_{n}^{*}, y_{n}^{*}\right) \times T\left(x_{n}^{*}, y_{n}^{*}\right)$ and a sequence $\varepsilon_{\mathrm{n}}>0$ with $\varepsilon_{\mathrm{n}} \rightarrow 0$ such that

$$
\begin{gathered}
\hat{d}\left(x_{n}, x_{n}^{*}\right) \leqslant \hat{d}\left(x_{n}, S\left(x_{n}, y_{n}\right)\right), \bar{d}\left(y_{n}, y_{n}^{*}\right) \leqslant \bar{d}\left(y_{n}, T\left(x_{n}, y_{n}\right)\right), \\
\begin{cases}0 \in G\left(p_{n}, x_{n}^{*}, y_{n}, u\right)+f\left(p_{n}, x_{n}^{*}, y_{n}\right)-f\left(p_{n}, u, y_{n}\right)+B^{+}\left(0, \varepsilon_{n}\right) \hat{e}\left(x_{n}^{*}\right), & \forall u \in S\left(x_{n}^{*}, y_{n}^{*}\right), \\
0 \in F\left(p_{n}, y_{n}^{*}, x_{n}, v\right)+g\left(p_{n}, x_{n}, y_{n}^{*}\right)-g\left(p_{n}, x_{n}, v\right)+B^{+}\left(0, \varepsilon_{n}\right) \bar{e}\left(y_{n}^{*}\right), & \forall v \in T\left(x_{n}^{*}, y_{n}^{*}\right) .\end{cases}
\end{gathered}
$$

For each $n \in \mathbf{N}$, let $\delta_{n}=d_{0}\left(p_{n}, p\right)$. Then, $p_{n} \in B\left(p, \delta_{n}\right)$ and $\left(x_{n}^{*}, y_{n}^{*}\right) \in \Omega_{p}\left(\delta_{n}, \varepsilon_{n}\right)$ for each $n \in \mathbf{N}$, and $\delta_{n} \rightarrow 0$ as $n \rightarrow \infty$. Let $\varepsilon>0$ be such that $\Omega_{p}(\varepsilon, \varepsilon)$ is a nonempty and bounded set satisfying condition (iv). Then there exists some $n_{0} \in \mathbf{N}$ such that $\left(x_{n}^{*}, y_{n}^{*}\right) \in \Omega_{\mathfrak{p}}\left(\delta_{n}, \varepsilon_{n}\right) \subseteq \Omega_{\mathfrak{p}}(\varepsilon, \varepsilon)$, for all $n \geqslant n_{0}$. Thus $\left\{\left(x_{n}^{*}, y_{n}^{*}\right)\right\}$ is bounded, and so there exists a subsequence $\left\{\left(x_{n_{k}}^{*}, y_{n_{k}}^{*}\right)\right\}$ of $\left\{\left(x_{n}^{*}, y_{n}^{*}\right)\right\}$ such that $\left(x_{n_{k}}^{*} y_{n_{k}}^{*}\right) \rightarrow\left(x^{*}, y^{*}\right)$ as $k \rightarrow \infty$. Then, by the similar arguments to those in the second part of the proof of Proposition 3.5, we can show that $\left(x^{*}, y^{*}\right) \in S\left(x^{*}, y^{*}\right) \times T\left(x^{*}, y^{*}\right)$ and

$$
\begin{cases}0 \in G\left(p, x^{*}, y^{*}, u\right)+f\left(p, x^{*}, y^{*}\right)-f\left(p, u, y^{*}\right), & \forall u \in S\left(x^{*}, y^{*}\right), \\ 0 \in F\left(p, y^{*}, x^{*}, v\right)+g\left(p, x^{*}, y^{*}\right)-g\left(p, x^{*}, v\right), & \forall v \in T\left(x^{*}, y^{*}\right) .\end{cases}
$$

Therefore $\left(x^{*}, y^{*}\right)$ is a solution of $(\text { SGMQVIP })_{p}$ and so $(S G M Q V I P)_{p}$ is well-posed in the generalized sense. This completes the proof.

If we set $f=0$ and $g=0$, then (SGMQVIP) reduces to (SGQVIP). For each $p \in P$, the approximating solution set for $(\mathrm{SGQVIP})_{\mathrm{p}}$ is defined by

$$
\begin{aligned}
\Omega_{p}(\delta, \varepsilon)=\bigcup_{p^{\prime} \in B(p, \delta)}\{ & \left(x^{*}, y^{*}\right) \in C \times D:\left(x^{*}, y^{*}\right) \in S\left(x^{*}, y^{*}\right) \times T\left(x^{*}, y^{*}\right), \text { and } \\
& \exists(x, y) \in S\left(x^{*}, y^{*}\right) \times T\left(x^{*}, y^{*}\right) \text { s.t. } \hat{d}\left(x, x^{*}\right) \leqslant \hat{d}(x, S(x, y)), \bar{d}\left(y, y^{*}\right) \leqslant \bar{d}(y, T(x, y)), \\
& 0 \in G\left(p^{\prime}, x^{*}, y, u\right)+B^{+}(0, \varepsilon) \hat{e}\left(x^{*}\right), \forall u \in S\left(x^{*}, y^{*}\right), \\
& \left.0 \in F\left(p^{\prime}, y^{*}, x, v\right)+B^{+}(0, \varepsilon) \bar{e}\left(y^{*}\right), \quad \forall v \in T\left(x^{*}, y^{*}\right)\right\}
\end{aligned}
$$

for all $\delta, \varepsilon>0$. Thus, by Theorems 3.7-3.11, we can obtain the following results of well-posedness for (SGQVIP). 
Theorem 3.12. Let $\mathrm{X}$ and $\mathrm{Y}$ be complete. Assume that

(i) $S$ and $T$ are continuous and compact-valued;

(ii) multivalued mappings $\mathrm{G}$ and $\mathrm{F}$ are closed;

(iii) for every $\mathrm{p} \in \mathrm{P}$, there exists $\Omega_{\mathfrak{p}}(\delta, \varepsilon)$ such that for each convergent sequence $\left\{\left(x_{\mathfrak{n}}^{*}, y_{\mathfrak{n}}^{*}\right)\right\} \subseteq \Omega_{\mathfrak{p}}(\delta, \varepsilon)$,

$$
\text { the convergence of }\left(x_{n}, y_{n}\right)\left(\in S\left(x_{n}^{*}, y_{n}^{*}\right) \times T\left(x_{n}^{*}, y_{n}^{*}\right), n \in N\right) \Rightarrow\left\{\begin{array}{l}
\hat{d}\left(x_{n}, S\left(x_{n}, y_{n}\right)\right) \rightarrow 0, \\
\bar{d}\left(y_{n}, T\left(x_{n}, y_{n}\right)\right) \rightarrow 0 .
\end{array}\right.
$$

Then (SGQVIP) is well-posed if and only if for every $p \in P, \Omega_{\mathfrak{p}}(\delta, \varepsilon) \neq \emptyset$ for all $\delta, \varepsilon>0$, and $\operatorname{diam}\left(\Omega_{\mathfrak{p}}(\delta, \varepsilon)\right) \rightarrow 0$ as $(\delta, \varepsilon) \rightarrow(0,0)$.

Theorem 3.13. Let $\mathrm{X}$ and $\mathrm{Y}$ be complete. Assume that

(i) $\mathrm{P}$ is finite-dimensional;

(ii) $\mathrm{S}$ and $\mathrm{T}$ are continuous and compact-valued;

(iii) multivalued mappings $\mathrm{G}$ and $\mathrm{F}$ are closed;

(iv) for every $\mathrm{p} \in \mathrm{P}$, there exists $\Omega_{\mathfrak{p}}(\delta, \varepsilon)$ such that for each convergent sequence $\left\{\left(x_{n}^{*}, y_{n}^{*}\right)\right\} \subseteq \Omega_{\mathfrak{p}}(\delta, \varepsilon)$,

$$
\text { the convergence of }\left(x_{n}, y_{n}\right)\left(\in S\left(x_{n}^{*}, y_{n}^{*}\right) \times T\left(x_{n}^{*}, y_{n}^{*}\right), n \in N\right) \Rightarrow\left\{\begin{array}{l}
\hat{d}\left(x_{n}, S\left(x_{n}, y_{n}\right)\right) \rightarrow 0, \\
\bar{d}\left(y_{n}, T\left(x_{n}, y_{n}\right)\right) \rightarrow 0 .
\end{array}\right.
$$

Then (SGQVIP) is well-posed in the generalized sense if and only if for every $p \in P, \Omega_{p}(\delta, \varepsilon) \neq \emptyset$, for all $\delta, \varepsilon>0$, and $\mu\left(\Omega_{\mathfrak{p}}(\delta, \varepsilon)\right) \rightarrow 0$ as $(\delta, \varepsilon) \rightarrow(0,0)$.

Theorem 3.14. Assume that all the conditions of Theorem 3.13 are satisfied. Then (SGQVIP) is well-posed in the generalized sense if and only if for every $\mathrm{p} \in \mathrm{P}, \mathrm{S}_{\mathrm{p}}$ is nonempty and compact and $\mathrm{e}\left(\Omega_{\mathrm{p}}(\delta, \varepsilon), \mathrm{S}_{\mathrm{p}}\right) \rightarrow 0$ as $(\delta, \varepsilon) \rightarrow(0,0)$.

Theorem 3.15. Let $\mathrm{X}$ and $\mathrm{Y}$ be finite-dimensional. Assume that

(i) $S$ and $\mathrm{T}$ are continuous and compact-valued;

(ii) multivalued mappings $\mathrm{G}$ and $\mathrm{F}$ are closed;

(iii) for every $p \in P$, there exists a nonempty and bounded set $\Omega_{p}(\varepsilon, \varepsilon)$ such that for each convergent sequence $\left\{\left(x_{n}^{*}, y_{n}^{*}\right)\right\} \subseteq \Omega_{p}(\varepsilon, \varepsilon)$, the convergence of $\left(x_{n}, y_{n}\right)\left(\in S\left(x_{n}^{*}, y_{n}^{*}\right) \times T\left(x_{n}^{*}, y_{n}^{*}\right), n \in N\right)$ implies $\hat{\mathrm{d}}\left(x_{n}, S\left(x_{n}, y_{n}\right)\right) \rightarrow 0$ and $\overline{\mathrm{d}}\left(y_{n}, T\left(x_{n}, y_{n}\right)\right) \rightarrow 0$.

Then $(\mathrm{SGQVIP})_{\mathrm{p}}$ is well-posed if and only if for every $\mathrm{p} \in \mathrm{P},(\mathrm{SGQVIP})_{\mathrm{p}}$ has a unique solution.

Theorem 3.16. Let $\mathrm{X}$ and $\mathrm{Y}$ be finite-dimensional. Assume that

(i) $\mathrm{S}$ and $\mathrm{T}$ are continuous and compact-valued;

(ii) multivalued mappings $\mathrm{G}$ and $\mathrm{F}$ are closed;

(iii) for every $\mathrm{p} \in \mathrm{P}$, there exists a nonempty and bounded set $\Omega_{\mathrm{p}}(\varepsilon, \varepsilon)$ such that for each convergent sequence $\left\{\left(x_{n}^{*}, y_{n}^{*}\right)\right\} \subseteq \Omega_{p}(\varepsilon, \varepsilon)$, the convergence of $\left(x_{n}, y_{n}\right)\left(\in S\left(x_{n}^{*}, y_{n}^{*}\right) \times T\left(x_{n}^{*}, y_{n}^{*}\right), n \in N\right)$ implies $\hat{\mathrm{d}}\left(x_{n}, \mathrm{~S}\left(\mathrm{x}_{n}, \mathrm{y}_{\mathrm{n}}\right)\right) \rightarrow 0$ and $\overline{\mathrm{d}}\left(\mathrm{y}_{n}, \mathrm{~T}\left(\mathrm{x}_{\mathrm{n}}, \mathrm{y}_{\mathrm{n}}\right)\right) \rightarrow 0$.

Then (SGQVIP $)_{p}$ is well-posed in the generalized sense if and only if for every $\mathrm{p} \in \mathrm{P},(\mathrm{SGQVIP})_{\mathrm{p}}$ has a nonempty solution set $\mathrm{S}_{\mathrm{p}}$.

Remark 3.17.

(a) Theorems 3.11-3.16 generalize and extend [26, Theorems 3.1-3.5] from (GQVIP) to (SGQVIP), respectively.

(b) Compared with [26, Theorem 3.3], our Theorem 3.14 is its corresponding one, which shows that if (SGQVIP) is well-posed in the generalized sense, then $S_{p}$ is compact for every $p \in P$, but such a corresponding conclusion cannot be concluded in [17]. 


\section{Well-posedness for optimization problems with constraints}

In this section, we study the well-posedness of optimization problems with systems of generalized mixed quasivariational inclusion problems as constraints.

Let $\mathcal{P}, X, Y$ and $W$ be normed spaces, and $K \subseteq W$ be a pointed, closed and convex cone with intK $\neq \emptyset$. Let $\mathrm{H}: \mathrm{P} \times \mathrm{C} \times \mathrm{D} \rightarrow 2^{\mathrm{W}}$ be a multivalued mapping with nonempty values. We consider the following optimization problem with the system of generalized mixed quasivariational inclusion problems as constraint:

$$
\text { (OPSGMQVIP) : } \operatorname{minH}(p, x, y) \text { subject to }(x, y) \in S_{p} \text {. }
$$

Let $M=\left\{(p, x, y) \in P \times C \times D:(x, y) \in S_{p}\right\}$. Suppose that $M$ is nonempty closed subset of $P \times C \times D$. A point $w \in H(M)$ is called a minimal point of $H(M)$ if $H(M) \cap(w-K \backslash\{0\})=\emptyset$. A point $(p, x, y) \in M$ is called an efficient solution of (OPSGMQVIP) if there exists $w \in \mathrm{H}(\mathrm{p}, x, y)$ such that $w$ is a minimal point of $\mathrm{H}(\mathrm{M})$.

For each $w, q \in W$ and each $\delta, \varepsilon>0$, let

$$
\mathrm{Q}(w):=\left\{(\mathrm{p}, \mathrm{x}, \mathrm{y}) \in \mathrm{P} \times \mathrm{C} \times \mathrm{D}:(\mathrm{x}, \mathrm{y}) \in \mathrm{S}_{\mathrm{p}}, w \in \mathrm{H}(\mathrm{p}, \mathrm{x}, \mathrm{y}) \text { and } \mathrm{H}(\mathrm{M}) \cap(w-\mathrm{K} \backslash\{0\})=\emptyset\right\},
$$

and $\mathrm{L}(w, \mathrm{q}, \delta, \varepsilon):=\mathrm{A}(w, \mathrm{q}, \delta) \cap \mathrm{D}(\varepsilon)$, where

$$
A(w, q, \delta):=\{(p, x, y) \in P \times C \times D: H(p, x, y) \cap(w+\delta q-K) \neq \emptyset\},
$$

and

$$
\begin{aligned}
D(\varepsilon):=\left\{\left(p, x^{*}, y^{*}\right)\right. & \in P \times C \times D:\left(x^{*}, y^{*}\right) \in S\left(x^{*}, y^{*}\right) \times T\left(x^{*}, y^{*}\right), \text { and } \exists(x, y) \in S\left(x^{*}, y^{*}\right) \times T\left(x^{*}, y^{*}\right) \text { s.t. } \\
& \hat{d}\left(x, x^{*}\right) \leqslant \hat{d}(x, S(x, y)), \bar{d}\left(y, y^{*}\right) \leqslant \bar{d}(y, T(x, y)), \\
& 0 \in G\left(p, x^{*}, y, u\right)+f\left(p, x^{*}, y\right)-f(p, u, y)+B^{+}(0, \varepsilon) \hat{e}\left(x^{*}\right), \forall u \in S\left(x^{*}, y^{*}\right), \\
& \left.0 \in F\left(p, y^{*}, x, v\right)+g\left(p, x, y^{*}\right)-g(p, x, v)+B^{+}(0, \varepsilon) \bar{e}\left(y^{*}\right), \quad \forall v \in T\left(x^{*}, y^{*}\right)\right\} .
\end{aligned}
$$

Clearly, for any $(w, q) \in W \times \operatorname{intK}, \delta_{1}, \delta_{2}>0$ with $\delta_{1} \leqslant \delta_{2}$ and $\varepsilon_{1}, \varepsilon_{2}>0$ with $\varepsilon_{1} \leqslant \varepsilon_{2}$, we have

(i) $\mathrm{A}\left(w, \mathrm{q}, \delta_{1}\right) \subseteq \mathrm{A}\left(w, \mathrm{q}, \delta_{2}\right)$;

(ii) $\mathrm{M} \subseteq \mathrm{D}\left(\varepsilon_{1}\right) \subseteq \mathrm{D}\left(\varepsilon_{2}\right)$;

(iii) $\mathrm{L}\left(w, \mathrm{q}, \delta_{1}, \varepsilon_{1}\right) \subseteq \mathrm{L}\left(w, \mathrm{q}, \delta_{2}, \varepsilon_{2}\right)$.

Definition 4.1. Let $\left\{k_{n}\right\} \subseteq W$ be a sequence with $k_{n} \rightarrow 0$ and $(p, x, y)$ be an efficient solution of (OPSGMQVIP). A sequence $\left\{\left(p_{n}, x_{n}, y_{n}\right)\right\} \subseteq P \times C \times D$ is said to be an approximating solution sequence for (OPSGMQVIP) corresponding to $\left\{k_{n}\right\}$ at $(p, x, y)$ if

(i) there exists $w \in \mathrm{H}(\mathrm{p}, \mathrm{x}, \mathrm{y})$ with $w$ being a minimal point of $\mathrm{H}(M)$ such that

$$
\mathrm{H}\left(\mathrm{p}_{\mathrm{n}}, \mathrm{x}_{\mathrm{n}}, \mathrm{y}_{\mathrm{n}}\right) \cap\left(w+\mathrm{k}_{\mathrm{n}}-\mathrm{K}\right) \neq \emptyset, \quad \forall \mathrm{n} \in \mathbf{N} ;
$$

(ii) there exists a sequence $\left\{\varepsilon_{n}\right\}$ of positive real numbers with $\varepsilon_{n} \rightarrow 0$ such that $\left(p_{n}, x_{n}, y_{n}\right) \in D\left(\varepsilon_{n}\right)$ for all $n \in \mathbf{N}$.

Definition 4.2. Let $q \in$ intK, $\left\{k_{n}\right\} \subseteq W$ be any sequence with $k_{n} \rightarrow 0$, and $(p, x, y)$ be an efficient solution of (OPSGMQVIP). Then (OPSGMQVIP) is said to be well-posed at $(p, x, y)$ if every approximating solution sequence for (OPSGMQVIP) corresponding to $\left\{k_{n}\right\}$ at $(p, x, y)$ converges to $(p, x, y)$.

Remark 4.3.

(a) When $(\mathrm{SGMQVIP})_{p}$ reduces to $(\mathrm{SGQVIP})_{p}$, (OPSGMQVIP) reduces to (OPSGQVIP) and therefore, by Definitions 4.1 and 4.2, we have definitions of approximating solution sequence and wellposedness for (OPSGQVIP). 
(b) The definition of approximating solution sequence for (OPSGQVIP) generalizes and extends that of Wang et al. [26].

(c) The definition of approximating solution sequence for (OPGQVIP) (including (OPVIP) as a special case) generalizes and extends that of Lin and Chuang [17].

Lemma 4.4 ([7]). Let $\left\{k_{n}\right\} \subseteq W$ be any sequence with $k_{n} \rightarrow 0$. Then, for every $q \in$ intK, there exists a sequence $\left\{\delta_{n}\right\}$ of positive real numbers with $\delta_{n} \rightarrow 0$ such that $\delta_{n} q-k_{n} \in$ intK for all $n \in \mathbf{N}$.

Proposition 4.5. Let $\mathrm{q} \in$ intK. If $\left(\mathrm{p}, x^{*}, \mathrm{y}^{*}\right) \in \mathrm{M}$ is an efficient solution of (OPSGMQVIP) and $w \in \mathrm{H}\left(\mathrm{p}, \mathrm{x}^{*}, \mathrm{y}^{*}\right)$ is a minimal point of $\mathrm{H}(\mathrm{M})$, then $\left(\mathrm{p}, \mathrm{x}^{*}, \mathrm{y}^{*}\right) \in \mathrm{L}(w, \mathrm{q}, \delta, \varepsilon)$ for all $\delta, \varepsilon>0$.

Proof. Let $\left(p, x^{*}, y^{*}\right) \in M$ be an efficient solution of (OPSGMQVIP) and $w \in \mathrm{H}\left(\mathrm{p}, \mathrm{x}^{*}, \mathrm{y}^{*}\right)$ be a minimal point of $H(M)$. Then $\left(x^{*}, y^{*}\right) \in S_{p}$ and $H(M) \cap(w-K \backslash\{0\})=\emptyset$. It follows that

$$
\left(x^{*}, y^{*}\right) \in S\left(x^{*}, y^{*}\right) \times T\left(x^{*}, y^{*}\right),
$$

and there exists $(x, y)=\left(x^{*}, y^{*}\right) \in S\left(x^{*}, y^{*}\right) \times T\left(x^{*}, y^{*}\right)$ such that

$$
\begin{gathered}
\hat{\mathrm{d}}\left(x, x^{*}\right) \leqslant \hat{\mathrm{d}}(x, S(x, y)), \overline{\mathrm{d}}\left(y, y^{*}\right) \leqslant \overline{\mathrm{d}}(y, T(x, y)), \\
\begin{cases}0 \in \mathrm{G}\left(\mathrm{p}, x^{*}, y, u\right)+f\left(p, x^{*}, y\right)-f(p, u, y)+B^{+}(0, \varepsilon) \hat{e}\left(x^{*}\right), & \forall u \in S\left(x^{*}, y^{*}\right), \\
0 \in \mathrm{F}\left(p, y^{*}, x, v\right)+g\left(p, x, y^{*}\right)-g(p, x, v)+B^{+}(0, \varepsilon) \bar{e}\left(y^{*}\right), & \forall v \in T\left(x^{*}, y^{*}\right),\end{cases}
\end{gathered}
$$

for any $\varepsilon>0$. Moreover, it is also clear that

$$
\mathrm{H}\left(\mathrm{p}, \mathrm{x}^{*}, \mathrm{y}^{*}\right) \cap(w-K)=\{w\}
$$

Hence $\left(p, x^{*}, y^{*}\right) \in D(\varepsilon)$. Taking into account $q \in$ intK, we have $-K \subseteq \delta q-K$ for any $\delta>0$. It follows from (4.1) that $w \in \mathrm{H}\left(\mathrm{p}, x^{*}, \mathrm{y}^{*}\right) \cap(w-\mathrm{K}) \subseteq \mathrm{H}\left(\mathrm{p}, x^{*}, \mathrm{y}^{*}\right) \cap(w+\delta \mathrm{q}-\mathrm{K})$. This implies that

$$
\mathrm{H}\left(\mathrm{p}, x^{*}, \mathrm{y}^{*}\right) \cap(w+\delta \mathrm{q}-\mathrm{K}) \neq \emptyset .
$$

Thus, $\left(p, x^{*}, y^{*}\right) \in A(w, q, \delta)$ and so $\left(p, x^{*}, y^{*}\right) \in L(w, q, \delta, \varepsilon)$. This completes the proof.

Theorem 4.6. Let $\mathrm{q} \in$ intK and $\left(\mathrm{p}, \mathrm{x}^{*}, \mathrm{y}^{*}\right) \in M$ be an efficient solution of (OPSGMQVIP). Then (OPSGMQVIP) is well-posed at $\left(\mathrm{p}, \mathrm{x}^{*}, \mathrm{y}^{*}\right)$ if and only if for every $w \in \mathrm{H}\left(\mathrm{p}, \mathrm{x}^{*}, \mathrm{y}^{*}\right)$ with $w$ being a minimal point of $\mathrm{H}(\mathrm{M})$,

$$
\operatorname{diam}(\mathrm{L}(w, \mathrm{q}, \delta, \varepsilon)) \rightarrow 0 \text { as }(\delta, \varepsilon) \rightarrow(0,0) .
$$

Proof. Suppose that (OPSGMQVIP) is well-posed at $\left(\mathrm{p}, \mathrm{x}^{*}, \mathrm{y}^{*}\right)$. Take any $w \in \mathrm{H}\left(\mathrm{p}, \mathrm{x}^{*}, \mathrm{y}^{*}\right)$ with $w$ being a minimal point of $\mathrm{H}(\mathrm{M})$ and let $w$ be fixed. If $\operatorname{diam}(\mathrm{L}(w, q, \delta, \varepsilon)) \not \rightarrow 0$ as $(\delta, \varepsilon) \rightarrow(0,0)$, then there exist a positive number $r$ and two sequences $\left\{\delta_{n}\right\}$ and $\left\{\varepsilon_{n}\right\}$ of positive real numbers and two sequences $\left\{\left(p_{n}^{1}, x_{n}^{1 *}, y_{n}^{1 *}\right)\right\}$ and $\left\{\left(p_{n}^{2}, x_{n}^{2 *}, y_{n}^{2 *}\right)\right\}$ in $P \times C \times D$ such that

(a) $\left(\delta_{n}, \varepsilon_{n}\right) \rightarrow(0,0)$ as $n \rightarrow \infty$;

(b) for each $n \in \mathbf{N},\left(p_{n}^{1}, x_{n}^{1 *}, y_{n}^{1 *}\right),\left(p_{n}^{2}, x_{n}^{2 *}, y_{n}^{2 *}\right) \in L\left(w, q, \delta_{n}, \varepsilon_{n}\right)$ and $\left\|\left(p_{n}^{1}, x_{n}^{1 *}, y_{n}^{1 *}\right)-\left(p_{n}^{2}, x_{n}^{2 *}, y_{n}^{2 *}\right)\right\| \geqslant r$;

(c) $\mathrm{H}\left(\mathrm{p}_{n}^{1}, x_{n}^{1 *}, y_{n}^{1 *}\right) \cap\left(w+\delta_{n} q-K\right) \neq \emptyset$ and $\mathrm{H}\left(p_{n}^{2}, x_{n}^{2 *}, y_{n}^{2 *}\right) \cap\left(w+\delta_{n} q-K\right) \neq \emptyset$;

(d) $\left(p_{n}^{1}, x_{n}^{1 *}, y_{n}^{1 *}\right),\left(p_{n}^{2}, x_{n}^{2 *}, y_{n}^{2 *}\right) \in D\left(\varepsilon_{n}\right)$.

By (a), $\delta_{n} q \rightarrow 0$ as $n \rightarrow \infty$. Then, by (c) and (d), $\left\{\left(p_{n}^{1}, x_{n}^{1 *}, y_{n}^{1 *}\right)\right\}$ and $\left\{\left(p_{n}^{2}, x_{n}^{2 *}, y_{n}^{2 *}\right)\right\}$ are both approximating solution sequences for (OPSGMQVIP) corresponding to $\left\{\delta_{n} q\right\}$ at $\left(p, x^{*}, y^{*}\right)$. Since (OPSGMQVIP) is well-posed at $\left(p, x^{*}, y^{*}\right),\left(p_{n}^{1}, x_{n}^{1 *}, y_{n}^{1 *}\right) \rightarrow\left(p, x^{*}, y^{*}\right)$ and $\left(p_{n}^{2}, x_{n}^{2 *}, y_{n}^{2 *}\right) \rightarrow\left(p, x^{*}, y^{*}\right)$ as $n \rightarrow \infty$. This leads to a contradiction. Thus $\operatorname{diam}(\mathrm{L}(w, q, \delta, \varepsilon)) \rightarrow 0$ as $(\delta, \varepsilon) \rightarrow(0,0)$.

Conversely, suppose that condition (4.2) holds. Let $\left\{k_{n}\right\} \subseteq W$ be any sequence with $k_{n} \rightarrow 0$. If $\left\{\left(p_{n}, x_{n}^{*}, y_{n}^{*}\right)\right\}$ is an approximating solution sequence for (OPSGMQVIP) corresponding to $\left\{k_{n}\right\}$ at $\left(p, x^{*}, y^{*}\right)$, then 
(a) there exists $w \in \mathrm{H}\left(\mathrm{p}, x^{*}, y^{*}\right)$ with $w$ being a minimal point of $\mathrm{H}(\mathrm{M})$ such that

$$
\mathrm{H}\left(\mathrm{p}_{\mathrm{n}}, \mathrm{x}_{\mathrm{n}}^{*}, \mathrm{y}_{\mathrm{n}}^{*}\right) \cap\left(w+\mathrm{k}_{\mathrm{n}}-\mathrm{K}\right) \neq \emptyset, \quad \forall \mathrm{n} \in \mathbf{N}
$$

(b) there exists a sequence $\left\{\varepsilon_{n}\right\}$ of positive real numbers with $\varepsilon_{n} \rightarrow 0$ such that $\left(p_{n}, x_{n}^{*}, y_{n}^{*}\right) \in D\left(\varepsilon_{n}\right)$ for all $n \in \mathbf{N}$.

By (a), for each $n \in \mathbf{N}$, there exists $w_{n} \in \mathrm{H}\left(\mathrm{p}_{n}, x_{n}^{*}, y_{n}^{*}\right)$ such that $w_{n} \in w+k_{n}-K$. Note that $\left\{k_{n}\right\} \subseteq W$ and $k_{n} \rightarrow 0$. By Lemma 4.4, there exists a sequence $\left\{\delta_{n}\right\}$ of positive real numbers with $\delta_{n} \rightarrow 0$ such that $k_{n} \in \delta_{n} q-$ intK. It follows that

$$
w_{n} \in w+k_{n}-K \subseteq w+\delta_{n} q-\text { intK }-K \subseteq w+\delta_{n} q-\text { intK }
$$

Hence $w_{n} \in H\left(p_{n}, x_{n}^{*}, y_{n}^{*}\right) \cap\left(w+\delta_{n} q-i n t K\right)$. This together with (b) implies that

$$
\left(p_{n}, x_{n}^{*}, y_{n}^{*}\right) \in L\left(w, q, \delta_{n}, \varepsilon_{n}\right) .
$$

Moreover, for each $\mathrm{n} \in \mathbf{N},\left(\mathrm{p}, \mathrm{x}^{*}, \mathrm{y}^{*}\right) \in \mathrm{M} \subseteq \mathrm{D}\left(\varepsilon_{\mathrm{n}}\right)$ and $w \in \mathrm{H}\left(\mathrm{p}, \mathrm{x}^{*}, \mathrm{y}^{*}\right) \cap\left(w+\delta_{n} \mathrm{q}-\mathrm{K}\right)$. Hence, $\left(p, x^{*}, y^{*}\right) \in L\left(w, q, \delta_{n}, \varepsilon_{n}\right)$ for every $n \in \mathbf{N}$. Then, we have

$$
\left\|\left(p_{n}, x_{n}^{*}, y_{n}^{*}\right)-\left(p, x^{*}, y^{*}\right)\right\| \leqslant \operatorname{diam}\left(L\left(w, q, \delta_{n}, \varepsilon_{n}\right)\right), \quad \forall n \in N .
$$

By the assumption, we get $\left(p_{n}, x_{n}^{*}, y_{n}^{*}\right) \rightarrow\left(p, x^{*}, y^{*}\right)$ and so (OPSGMQVIP) is well-posed at $\left(p, x^{*}, y^{*}\right)$. This completes the proof.

Theorem 4.7. Let $\mathrm{P}, \mathrm{C}$ and $\mathrm{D}$ be finite-dimensional. Let $\mathrm{q} \in \operatorname{intK}$ and let $\left(\mathrm{p}, \mathrm{x}^{*}, \mathrm{y}^{*}\right) \in \mathrm{M}$ be an efficient solution of (OPSGMQVIP). Assume that

(i) $\mathrm{H}$ is u.s.c. and compact-valued and $\mathrm{S}, \mathrm{T}$ are continuous and compact-valued;

(ii) single-valued mappings $f$ and $g$ are continuous;

(iii) multivalued mappings $\mathrm{G}$ and $\mathrm{F}$ are closed;

(iv) for every $w \in \mathrm{H}\left(\mathrm{p}, \mathrm{x}^{*}, \mathrm{y}^{*}\right)$ with $w$ being a minimal point of $\mathrm{H}(\mathrm{M})$, there exists a nonempty and bounded set $\mathrm{L}(w, \mathrm{q}, \varepsilon, \varepsilon)$ such that for each convergent sequence $\left\{\left(\mathrm{p}_{\mathrm{n}}, \mathrm{x}_{\mathrm{n}}^{*}, \mathrm{y}_{\mathrm{n}}^{*}\right)\right\} \subseteq \mathrm{L}(w, \mathrm{q}, \varepsilon, \varepsilon)$,

$$
\text { the convergence of }\left(x_{n}, y_{n}\right)\left(\in S\left(x_{n}^{*}, y_{n}^{*}\right) \times T\left(x_{n}^{*}, y_{n}^{*}\right), n \in N\right) \Rightarrow\left\{\begin{array}{l}
\hat{d}\left(x_{n}, S\left(x_{n}, y_{n}\right)\right) \rightarrow 0, \\
\bar{d}\left(y_{n}, T\left(x_{n}, y_{n}\right)\right) \rightarrow 0
\end{array}\right.
$$

Then (OPSGMQVIP) is well-posed at $\left(\mathrm{p}, \mathrm{x}^{*}, \mathrm{y}^{*}\right)$ if and only if for every $\mathrm{w} \in \mathrm{H}\left(\mathrm{p}, \mathrm{x}^{*}, \mathrm{y}^{*}\right)$ with $w$ being a minimal point of $\mathrm{H}(\mathrm{M}), \mathrm{Q}(w)=\left\{\left(\mathrm{p}, \mathrm{x}^{*}, \mathrm{y}^{*}\right)\right\}$.

Proof. Suppose that (OPSGMQVIP) is well-posed at $\left(\mathrm{p}, \mathrm{x}^{*}, \mathrm{y}^{*}\right)$. Take any $w \in \mathrm{H}\left(\mathrm{p}, \mathrm{x}^{*}, \mathrm{y}^{*}\right)$ with $w$ being a minimal point of $\mathrm{H}(M)$ and let $w$ be fixed. Clearly, $\left(p, x^{*}, y^{*}\right) \in Q(w)$. Moreover, if $\left(p^{\prime}, x^{\prime}, y^{\prime}\right) \in Q(w)$, then $\left(x^{\prime}, y^{\prime}\right) \in S_{p^{\prime}}, w \in H\left(p^{\prime}, x^{\prime}, y^{\prime}\right)$ and $H(M) \cap(w-K \backslash\{0\})=\emptyset$. It follows that

$$
\left(p^{\prime}, x^{\prime}, y^{\prime}\right) \in M \text { and } H\left(p^{\prime}, x^{\prime}, y^{\prime}\right) \cap(w-K)=\{w\} .
$$

For each $n \in \mathbf{N}$, let $k_{n}=0, p_{n}=p^{\prime}, x_{n}^{*}=x^{\prime}$ and $y_{n}^{*}=y^{\prime}$. Then $k_{n} \rightarrow 0$ and $\left\{\left(p_{n}, x_{n}^{*}, y_{n}^{*}\right)\right\}$ is an approximating solution sequence for (OPSGMQVIP) corresponding to $\left\{k_{n}\right\}$ at $\left(p, x^{*}, y^{*}\right)$. Since (OPSGMQVIP) is well-posed at $\left(p, x^{*}, y^{*}\right),\left(p_{n}, x_{n}^{*}, y_{n}^{*}\right) \rightarrow\left(p, x^{*}, y^{*}\right)$ as $n \rightarrow \infty$. This implies that $\left(p^{\prime}, x^{\prime}, y^{\prime}\right)=\left(p, x^{*}, y^{*}\right)$ and so $Q(w)=\left\{\left(p, x^{*}, y^{*}\right)\right\}$.

Conversely, suppose that, for every $w \in \mathrm{H}\left(\mathrm{p}, x^{*}, \mathrm{y}^{*}\right)$ with $w$ being a minimal point of $\mathrm{H}(\mathrm{M}), \mathrm{Q}(w)=$ $\left\{\left(p, x^{*}, y^{*}\right)\right\}$. Let $\left\{k_{n}\right\} \subseteq W$ be any sequence with $k_{n} \rightarrow 0$. If $\left\{\left(p_{n}, x_{n}^{*}, y_{n}^{*}\right)\right\} \subseteq P \times C \times D$ is an approximating solution sequence for (OPSGMQVIP) corresponding to $\left\{k_{n}\right\}$ at $\left(p, x^{*}, y^{*}\right)$, then 
(a) there exists $w \in H\left(p, x^{*}, y^{*}\right)$ with $w$ being a minimal point of $H(M)$ such that

$$
\mathrm{H}\left(\mathrm{p}_{\mathrm{n}}, \mathrm{x}_{\mathrm{n}}^{*}, \mathrm{y}_{\mathrm{n}}^{*}\right) \cap\left(w+\mathrm{k}_{\mathrm{n}}-\mathrm{K}\right) \neq \emptyset, \quad \forall \mathrm{n} \in \mathbf{N}
$$

(b) there exists a sequence $\left\{\varepsilon_{n}\right\}$ of positive real numbers with $\varepsilon_{n} \rightarrow 0$ such that $\left(p_{n}, x_{n}^{*}, y_{n}^{*}\right) \in D\left(\varepsilon_{n}\right)$ for all $n \in \mathbf{N}$.

By (a), for each $n \in \mathbf{N}$, there exists $z_{n} \in H\left(p_{n}, x_{n}^{*}, y_{n}^{*}\right)$ such that $z_{n} \in w+k_{n}-K$. Note that $\left\{k_{n}\right\} \subseteq W$ and $k_{n} \rightarrow 0$. By Lemma 4.4, there exists a sequence $\left\{\delta_{n}\right\}$ of positive real numbers with $\delta_{n} \rightarrow 0$ such that $k_{n} \in \delta_{n} q-$ intK. Hence

$$
z_{n} \in w+k_{n}-K \subseteq w+\delta_{n} q-\text { intK }-K \subseteq w+\delta_{n} q-\text { intK }
$$

It follows that

$$
z_{n} \in H\left(p_{n}, x_{n}^{*}, y_{n}^{*}\right) \cap\left(w+\delta_{n} q-\operatorname{intK}\right)
$$

This together with (b) implies that $\left(p_{n}, x_{n}^{*}, y_{n}^{*}\right) \in L\left(w, q, \delta_{n}, \varepsilon_{n}\right)$. Let $L(w, q, \varepsilon, \varepsilon)$ be a nonempty and bounded set satisfying condition (iv). Then there exists some $n_{0} \in \mathbf{N}$ such that

$$
\left(\mathrm{p}_{\mathrm{n}}, \mathrm{x}_{\mathrm{n}}^{*}, \mathrm{y}_{\mathrm{n}}^{*}\right) \in \mathrm{L}\left(w, \mathrm{q}, \delta_{\mathrm{n}}, \varepsilon_{\mathrm{n}}\right) \subseteq \mathrm{L}(w, \mathrm{q}, \varepsilon, \varepsilon), \quad \forall \mathrm{n} \geqslant \mathrm{n}_{0}
$$

and so $\left\{\left(p_{n}, x_{n}^{*}, y_{n}^{*}\right)\right\}$ is bounded. Also, since for each $n \in N,\left(p_{n}, x_{n}^{*}, y_{n}^{*}\right) \in L\left(w, q, \delta_{n}, \varepsilon_{n}\right) \subseteq D\left(\varepsilon_{n}\right)$, it follows that $\left(x_{n}, y_{n}\right) \in S\left(x_{n}^{*}, y_{n}^{*}\right) \times T\left(x_{n}^{*}, y_{n}^{*}\right)$, and there exists $\left(x_{n}, y_{n}\right) \in S\left(x_{n}^{*}, y_{n}^{*}\right) \times T\left(x_{n}^{*}, y_{n}^{*}\right)$ such that

$$
\begin{gathered}
\hat{d}\left(x_{n}, x_{n}^{*}\right) \leqslant \hat{d}\left(x_{n}, S\left(x_{n}, y_{n}\right)\right), \quad \bar{d}\left(y_{n}, y_{n}^{*}\right) \leqslant \bar{d}\left(y_{n}, T\left(x_{n}, y_{n}\right)\right), \\
\begin{cases}0 \in G\left(p_{n}, x_{n}^{*}, y_{n}, u\right)+f\left(p_{n}, x_{n}^{*}, y_{n}\right)-f\left(p_{n}, u, y_{n}\right)+B^{+}\left(0, \varepsilon_{n}\right) \hat{e}\left(x_{n}^{*}\right), & \forall u \in S\left(x_{n}^{*}, y_{n}^{*}\right), \\
0 \in F\left(p_{n}, y_{n}^{*}, x_{n}, v\right)+g\left(p_{n}, x_{n}, y_{n}^{*}\right)-g\left(p_{n}, x_{n}, v\right)+B^{+}\left(0, \varepsilon_{n}\right) \bar{e}\left(y_{n}^{*}\right), & \forall v \in T\left(x_{n}^{*}, y_{n}^{*}\right) .\end{cases}
\end{gathered}
$$

Let $\left\{\left(p_{n_{k}}, x_{n_{k}}^{*}, y_{n_{k}}^{*}\right)\right\}$ be any subsequence of $\left\{\left(p_{n}, x_{n}^{*}, y_{n}^{*}\right)\right\}$ such that $\left(p_{n_{k}}, x_{n_{k}}^{*}, y_{n_{k}}^{*}\right) \rightarrow(\tilde{p}, \tilde{x}, \tilde{y})$ as $k \rightarrow \infty$ for some $(\tilde{p}, \tilde{x}, \tilde{y}) \in P \times C \times D$. Then, by the similar arguments to those in the second part of the proof of Proposition 3.5, we can show that $(\tilde{x}, \tilde{y}) \in S(\tilde{x}, \tilde{y}) \times T(\tilde{x}, \tilde{y})$ such that

$$
\begin{cases}0 \in \mathrm{G}(\tilde{\mathrm{p}}, \tilde{x}, \tilde{y}, u)+f(\tilde{p}, \tilde{x}, \tilde{y})-f(\tilde{p}, u, \tilde{y}), & \forall u \in S(\tilde{x}, \tilde{y}), \\ 0 \in \mathrm{F}(\tilde{p}, \tilde{y}, \tilde{x}, v)+g(\tilde{p}, \tilde{x}, \tilde{y})-g(\tilde{p}, \tilde{x}, v), & \forall v \in T(\tilde{x}, \tilde{y}) .\end{cases}
$$

It follows that $(\tilde{x}, \tilde{y}) \in S_{\tilde{p}}$, i.e., $(\tilde{p}, \tilde{x}, \tilde{y}) \in M$. Moreover, by (4.3), we have $z_{n_{k}} \in H\left(p_{n_{k}}, x_{n_{k}}^{*}, y_{n_{k}}^{*}\right)$ and $z_{n_{k}}-w-\delta_{n_{k}} q \in-K$. Since $H$ is u.s.c. and compact-valued, we may assume that $z_{n_{k}} \rightarrow \tilde{z} \in H(\tilde{p}, \tilde{x}, \tilde{y})$. Clearly $\delta_{n_{k}} q \rightarrow 0$ as $k \rightarrow \infty$. Then, we have $\tilde{z}-w \in-K$, i.e., $\tilde{z} \in w-K$. This implies that $\tilde{z} \in$ $\mathrm{H}(\tilde{\mathrm{p}}, \tilde{x}, \tilde{y}) \cap(w-K)$. Noting that $w \in \mathrm{H}\left(\mathrm{p}, x^{*}, y^{*}\right)$ is a minimal point of $\mathrm{H}(M)$, we get

$$
\tilde{z} \in \mathrm{H}(\tilde{\mathrm{p}}, \tilde{x}, \tilde{y}) \cap(w-K) \subseteq \mathrm{H}(M) \cap(w-K)=\{w\} .
$$

It follows that $\tilde{z}=w$, and so $\mathrm{H}(\tilde{\mathrm{p}}, \tilde{\mathrm{x}}, \tilde{y}) \cap(w-K)=\mathrm{H}(M) \cap(w-K)=\{w\}$. Hence,

$$
w \in H(\tilde{p}, \tilde{x}, \tilde{y}) \text { and } H(M) \cap(w-K \backslash\{0\})=\emptyset .
$$

This implies that $(\tilde{p}, \tilde{x}, \tilde{y}) \in Q(w)=\left\{\left(p, x^{*}, y^{*}\right)\right\}$. Thus, $(\tilde{p}, \tilde{x}, \tilde{y})=\left(p, x^{*}, y^{*}\right)$, and so the whole sequence $\left\{\left(p_{n}, x_{n}^{*}, y_{n}^{*}\right)\right\}$ converges to $\left(p, x^{*}, y^{*}\right)$. Therefore (OPSGMQVIP) is well-posed at $\left(p, x^{*}, y^{*}\right)$. This completes the proof.

If we set $f=0$ and $g=0$, then (SGMQVIP) reduces to (SGQVIP). For each $p \in P$, by $S_{p}$ we denote the solution set of (SGQVIP). In this case, for all $\varepsilon>0$ we have 


$$
\begin{aligned}
D(\varepsilon):=\left\{\left(p, x^{*}, y^{*}\right) \in P \times C \times D\right. & :\left(x^{*}, y^{*}\right) \in S\left(x^{*}, y^{*}\right) \times T\left(x^{*}, y^{*}\right), \text { and } \exists(x, y) \in S\left(x^{*}, y^{*}\right) \times T\left(x^{*}, y^{*}\right) \text { s.t. } \\
& \hat{d}\left(x, x^{*}\right) \leqslant \hat{d}(x, S(x, y)), \bar{d}\left(y, y^{*}\right) \leqslant \bar{d}(y, T(x, y)) \\
& 0 \in G\left(p, x^{*}, y, u\right)+B^{+}(0, \varepsilon) \hat{e}\left(x^{*}\right), \forall u \in S\left(x^{*}, y^{*}\right) \\
& \left.0 \in F\left(p, y^{*}, x, v\right)+B^{+}(0, \varepsilon) \bar{e}\left(y^{*}\right), \quad \forall v \in T\left(x^{*}, y^{*}\right)\right\} .
\end{aligned}
$$

Thus, by Theorems 4.6 and 4.7, we can obtain the following results of well-posedness for (OPSGQVIP).

Theorem 4.8. Let $\mathrm{q} \in \operatorname{intK}$ and let $\left(\mathrm{p}, \mathrm{x}^{*}, \mathrm{y}^{*}\right) \in M$ be an efficient solution of (OPSGQVIP). Then (OPSGQVIP) is well-posed at $\left(\mathrm{p}, \mathrm{x}^{*}, \mathrm{y}^{*}\right)$ if and only if for every $\mathrm{w} \in \mathrm{H}\left(\mathrm{p}, \mathrm{x}^{*}, \mathrm{y}^{*}\right)$ with $\mathrm{w}$ being a minimal point of $\mathrm{H}(\mathrm{M})$,

$$
\operatorname{diam}(\mathrm{L}(w, \mathrm{q}, \delta, \varepsilon)) \rightarrow 0 \text { as }(\delta, \varepsilon) \rightarrow(0,0) .
$$

Theorem 4.9. Let $\mathrm{q} \in \mathrm{intK}$ and let $\left(\mathrm{p}, \mathrm{x}^{*}, \mathrm{y}^{*}\right) \in \mathrm{M}$ be an efficient solution of (OPSGQVIP). Assume that

(i) $\mathrm{P}, \mathrm{C}$ and $\mathrm{D}$ are finite-dimensional;

(ii) $\mathrm{H}$ is u.s.c. and compact-valued and $\mathrm{S}, \mathrm{T}$ are continuous and compact-valued;

(iii) multivalued mappings $\mathrm{G}$ and $\mathrm{F}$ are closed;

(iv) for every $w \in \mathrm{H}\left(\mathrm{p}, x^{*}, \mathrm{y}^{*}\right)$ with $w$ being a minimal point of $\mathrm{H}(\mathrm{M})$, there exists a nonempty and bounded set $\mathrm{L}(w, q, \varepsilon, \varepsilon)$ such that for each convergent sequence $\left\{\left(p_{n}, x_{n}^{*}, y_{n}^{*}\right)\right\} \subseteq L(w, q, \varepsilon, \varepsilon)$,

$$
\text { the convergence of }\left(x_{n}, y_{n}\right)\left(\in S\left(x_{n}^{*}, y_{n}^{*}\right) \times T\left(x_{n}^{*}, y_{n}^{*}\right), n \in N\right) \Rightarrow\left\{\begin{array}{l}
\hat{d}\left(x_{n}, S\left(x_{n}, y_{n}\right)\right) \rightarrow 0 \\
\bar{d}\left(y_{n}, T\left(x_{n}, y_{n}\right)\right) \rightarrow 0
\end{array}\right.
$$

Then (OPSGQVIP) is well-posed at $\left(\mathrm{p}, \mathrm{x}^{*}, \mathrm{y}^{*}\right)$ if and only if for every $w \in \mathrm{H}\left(\mathrm{p}, \mathrm{x}^{*}, \mathrm{y}^{*}\right)$ with $w$ being a minimal point of $\mathrm{H}(\mathrm{M}), \mathrm{Q}(w)=\left\{\left(\mathrm{p}, x^{*}, \mathrm{y}^{*}\right)\right\}$.

Remark 4.10.

(a) Theorems 4.8-4.9 generalize and extend [26, Theorems 4.1-4.2] from (OPGQVIP) to (OPSGQVIP), respectively.

(b) Compared with [26, Theorems 4.1-4.2], our Theorems 4.6-4.7 are their corresponding ones, which show that for the well-posedness of (OPSGQVIP), the necessary condition coincides with the sufficient one. But, for the well-posedness of (OPVIP), Lin and Chuang [17] gave necessary condition and sufficient condition, respectively. It is worth mentioning that their necessary condition is different from the sufficient one.

\section{Acknowledgment}

This research was partially supported by the Innovation Program of Shanghai Municipal Education Commission (15ZZ068), Ph.D. Program Foundation of Ministry of Education of China (20123127110002) and Program for Outstanding Academic Leaders in Shanghai City (15XD1503100). Yeong-Cheng Liou was supported in part by the grand form Kaohsiung Medical University Research Foundation (KMUQ106005), Taiwan-Thailand joint grant MOST 106-2218-E-040-001-MY2 and Taiwan-Russian joint grant MOST 106-2923-E-039-001-MY3. J. C. Yao was partially supported by the Grant MOST 106-2923-E-039001-MY3.

\section{References}

[1] J.-P. Aubin, I. Ekeland, Applied Nonlinear Analysis, John Wiley \& Sons, New York, (1984). 2.1, 2.2

[2] M. Bianchi, G. Kassay, R. Pini, Well-posed equilibrium problems, Nonlinear Anal., 72 (2010), 460-468. 1

[3] L.-C. Ceng, Y.-C. Lin, Metric characterizations of $\alpha$-well-posedness for a system of mixed quasivariational-like inequalities in Banach spaces, J. Appl. Math., 2012 (2012), 22 pages. 1 
[4] L.-C. Ceng, Y.-C. Liou, J.-C. Yao, Y.-H. Yao, Well-posedness for systems of time-dependent hemivariational inequalities in Banach spaces, J. Nonlinear Sci. Appl., 10 (2017), 4318-4336. 1

[5] L.-C. Ceng, J.-C. Yao, Well-posedness of generalized mixed variational inequalities, inclusion problems and fixed-point problems, Nonlinear Anal., 69 (2008), 4585-4603. 1

[6] G. P. Crespi, A. Guerraggio, M. Rocca, Well-posedness in vector optimization problems and vector variational inequalities, J. Optim. Theory Appl., 132 (2007), 213-226. 1

[7] M. Durea, Scalarization for pointwise well-posed vectorial problems, Math. Methods Oper. Res., 66 (2007), 409-418. 4.4

[8] Y.-P. Fang, R. Hu, N.-J. Huang, Well-posedness for equilibrium problems and for optimization problems with equilibrium constraints, Comput. Math. Appl., 55 (2008), 89-100. 1

[9] Y.-P. Fang, N.-J. Huang, J.-C. Yao, Well-posedness of mixed variational inequalities, inclusion problems and fixed-point problems, J. Global Optim., 41 (2008), 117-133. 1

[10] Y.-P. Fang, N.-J. Huang, J.-C. Yao, Well-posedness by perturbations of mixed variational inequalities in Banach spaces, European J. Oper. Res., 201 (2010), 682-692. 1

[11] F. Giannessi, P. M. Pardalos, T. Rapcsak, New Trends in Equilibrium Systems, Kluwer Academic Publishers, Dordrecht, (2001). 1

[12] N. X. Hai, P. Q. Khanh, The solution existence of general variational inclusion problems, J. Math. Anal. Appl., 328 (2007), 1268-1277. 1

[13] X. X. Huang, X. Q. Yang, D. L. Zhu, Levitin-Polyak well-posedness of variational inequality problems with functional constraints, J. Global Optim., 44 (2009), 159-174. 1

[14] K. Kuratowski, Topology, Academic Press, New York, (1968). 2.3, 2.4, 3

[15] B. Lemaire, C. O. A. Salem, J. P. Revalski, Well-posedness by perturbations of variational problems, J. Optim. Theory Appl., 115 (2002), 345-368. 1

[16] M. B. Lignola, Well-posedness and L-well-posedness for quasivariational inequalities, J. Optim. Theory Appl., 128 (2006), 119-138. 1

[17] L.-J. Lin, C.-S. Chuang, Well-posedness in the generalized sense for variational inclusion and disclusion problems and well-posedness for optimization problems with constraint, Nonlinear Anal., 70 (2009), 3609-3617. 1, 3.3, 3.17, 4.3, 4.10

[18] X.-J. Long, N.-J. Huang, Metric characterizations of $\alpha$-well-posedness for symmetric quasiequilibrium problems, J. Global Optim., 45 (2009), 459-471. 1

[19] R. Lucchetti, F. Patrone, A characterization of Tykhonov well-posedness for minimum problems with applications to variational inequalities, Numer. Funct. Anal. Optim., 3 (1981), 461-476. 1

[20] M. Margiocco, F. Patrone, L. Pusillo Chicco, A new approach to Tikhonov well-posedness for Nash equilibria, Optim., 40 (1997), 385-400. 1

[21] J. Morgan, Approximations and well-posedness in multicriteria games, Ann. Oper. Res., 137 (2005), 257-268. 1

[22] A. Petruşel, I. A. Rus, J.-C. Yao, Well-posedness in the generalized sense of the fixed point problems for multivalued operators, Taiwanese J. Math., 11 (2007), 903-914. 1

[23] J. P. Revalski, Hadamard and strong well-posedness for convex programs, SIAM J. Optim., 7 (1997), 519-526. 1

[24] P. H. Sach, L. A. Tuan, Generalizations of vector quasivariational inclusion problems with set-valued maps, J. Global Optim., 43 (2009), 23-45. 1

[25] A. N. Tikhonov, On the stability of the functional optimization problems, USSR J. Comput. Math. Math. Phys., 6 (1966), 28-33. 1

[26] S.-H. Wang, N.-J. Huang, D. O'Regan, Well-posedness for generalized quasi-variational inclusion problems and for optimization problems with constraints, J. Global Optim., 55 (2013), 189-208. 1, 3.3, 3.17, 4.3, 4.10

[27] Y.-H. Yao, M. A. Noor, Y.-C. Liou, S. M. Kang, Iterative algorithms for general multi-valued variational inequalities, Abstr. Appl. Anal., 2012 (2012), 10 pages. 1

[28] Y.-H. Yao, M. Postolache, Y.-C. Liou, Z.-S. Yao, Construction algorithms for a class of monotone variational inequalities, Optim. Lett., 10 (2016), 1519-1528. 1

[29] Y.-H. Yao, N. Shahzad, Strong convergence of a proximal point algorithm with general errors, Optim. Lett., 6 (2012), 621-628. 1

[30] Y.-H. Yao, N. Shahzad, An algorithmic approach to the split variational inequality and fixed point problem, J. Nonlinear Convex Anal., 18 (2017), 977-991. 1

[31] H. Zegeye, N. Shahzad, Y.-H. Yao, Minimum-norm solution of variational inequality and fixed point problem in Banach spaces, Optimization, 64 (2015), 453-471. 1

[32] T. Zolezzi, Well-posedness criteria in optimization with application to the calculus of variations, Nonlinear Anal., 25 (1995), 437-453. 1

[33] T. Zolezzi, Extended well-posedness of optimization problems, J. Optim. Theory Appl., 91 (1996), 257-266. 1 